\title{
Survival, neuron-like differentiation and functionality of mesenchymal stem cells in neurotoxic environment: the critical role of erythropoietin
}

\author{
L Danielyan ${ }^{\star, 1,10}$, R Schäfer ${ }^{\star 2,210}$, A Schulz ${ }^{3}$, T Ladewig ${ }^{4}$, A Lourhmati ${ }^{1}$, M Buadze $^{1}$, AL Schmitt ${ }^{1}$, S Verleysdonk ${ }^{5}$, D Kabisch ${ }^{1}$,

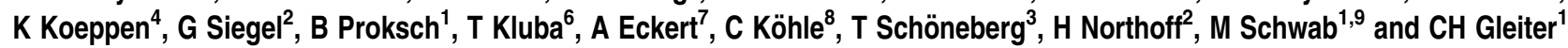

Mesenchymal stem cells (MSCs) can ameliorate symptoms in several neurodegenerative diseases. However, the toxic environment of a degenerating central nervous system (CNS) characterized by hypoxia, glutamate (Glu) excess and amyloid beta (Abeta) pathology may hamper the survival and regenerative/replacing capacities of engrafted stem cells. Indeed, human MSC (hMSC) exposed to hypoxia were disabled in (i) the capacity of their muscarinic receptors (mAChRs) to respond to acetylcholine $(A C h)$ with a transient increase in intracellular $\left[\mathrm{Ca}^{2+}\right.$, (ii) their capacity to metabolize Glu, reflected by a strong decrease in glutamine synthetase activity, and (iii) their survival on exposure to Glu. Cocultivation of MSC with PC12 cells expressing the amyloid precursor protein gene (APPsw-PC12) increased the release of IL-6 from MSC. HMSC exposed to erythropoietin (EPO) showed a cholinergic neuron-like phenotype reflected by increased cellular levels of choline acetyltransferase, ACh and mAChR. All their functional deficits observed under hypoxia, Glu exposure and APPsw-PC12 cocultivation were reversed by the application of EPO, which increased the expression of Wnt3a. EPO also enhanced the metabolism of Abeta in MSC by increasing their neprilysin content. Our data show that cholinergic neuron-like differentiation of MSC, their functionality and resistance to a neurotoxic environment is regulated and can be improved by EPO, highlighting its potential for optimizing cellular therapies of the CNS.

Cell Death and Differentiation (2009) 16, 1599-1614; doi:10.1038/cdd.2009.95; published online 17 July 2009

The concept of stem cell therapy is based on the mainstream idea of protecting the parenchymal cells of a diseased host organ and replacing those that have already failed in their function. As candidates for the treatment of neurodegenerative diseases, bone marrow (BM)-derived mesenchymal stem cells (MSCs) possess numerous protective features as well as the capability to differentiate into functionally specialized neurons. ${ }^{1}$ They have been successfully applied in experimental models of cerebral ischemia ${ }^{2}$ and Parkinson's disease (PD). ${ }^{3}$ The benefit of MSC for the therapy of PD are likely due to their capability to differentiate into dopaminergic neurons. ${ }^{4}$ The potential of MSC may not be restricted to the generation of only one type of specialized neurons. The identification of conditions under which they differentiate into other types of neurons would greatly enhance their potential therapeutic value.

As the successful transplantation of stem cells into a diseased organ requires their capacity not only to survive in the diseased environment but also to protect or replace host cells in their function, the response of stem cells to the pathological environment specific for the diseased host organ has to be considered. Among the common factors occurring in a broad range of neurodegenerative diseases, hypoxia and glutamate (Glu) excess have a prominent role in maintaining the pathological milieu and exacerbate the disease. Hypoxia enhances the production of amyloid beta (Abeta) and the

\footnotetext{
${ }^{1}$ Department of Clinical Pharmacology, University Hospital of Tübingen, Tübingen, Germany; ${ }^{2}$ Institute of Clinical and Experimental Transfusion Medicine, University Hospital of Tübingen, Tübingen, Germany; ${ }^{3}$ Institute of Biochemistry, Medical Faculty, University of Leipzig, Leipzig, Germany; ${ }^{4}$ Center for Ophthalmology, University Hospital of Tübingen, Tübingen, Germany; ${ }^{5}$ Interfaculty Institute for Biochemistry, University of Tübingen, Tübingen, Germany; ${ }^{6}$ Department of Orthopaedics, University Hospital of Tübingen, Tübingen, Germany; ${ }^{7}$ Neurobiology Research Laboratory, Psychiatric University Clinics, Basel, Switzerland; ${ }^{8}$ Department of Toxicology, Institute of Pharmacology and Toxicology, University of Tübingen, Tübingen, Germany and ${ }^{9} \mathrm{Dr}$ Margarete Fischer-Bosch-Institute of Clinical Pharmacology, University of Tübingen, Stuttgart, Germany

${ }^{*}$ Corresponding author: L Danielyan, Department of Clinical Pharmacology, University Hospital of Tüebingen, Ottried-Müeller Str.45, Tüebingen, 72076, Germany. Tel: + 49707129 74926; Fax: + 49707129 5035; E-mail: lusine.danielyan @ med.uni-tuebingen.de or R Schäfer, Institute of Clinical and Experimental Transfusion Medicine, University Hospital of Tübingen, Otfried-Müller Str. 4/1, Germany. Tel: + 497071 2981665; Fax: + 497071 295240; Email: richard.schaefer@med.uni-tuebingen.de

${ }^{10}$ The authors contributed equally to this work

Keywords: erythropoietin; hypoxia; MSCs; Abeta; cholinergic differentiation; glutamate

Abbreviations: Abeta, amyloid beta; ACh, acetylcholine; APPsw, amyloid precursor protein Swedish mutation; ChAT, choline acetyltranferase; CRD Fzd 7, cystein-rich domain of frizzled 7; DMEM, Dulbecco's modified Eagle's medium; EPO, erythropoietin; EPOR, erythropoietin receptor; EPI, erythropoietin preincubation; FCS, fetal calf serum; GLAST, glutamate-aspartate transporter; Glu, glutamate; GS, glutamine synthetase; H, hypoxia; HCs, hypoxic conditions; LDH, lactate dehydrogenase; LIF, leukemia-inhibitory factor; M1R, muscarinic receptor subtype 1; M1R-M3R, muscarinic receptors of type 1-3; MSCs, mesenchymal stem cells; N, normoxia; NCs, normoxic conditions; NeuN, neuronal nuclei-specific protein; NGF, nerve growth factor; PBS, phosphate-buffered saline; ROX, carboxy-X-rhodamine; TUNEL, terminal deoxynucleotide transferase-mediated dUTP-biotin nick end labeling.

Received 03.3.09; revised 08.5.09; accepted 17.6.09; Edited by SA Lipton; published online 17.7.09
} 
likelihood of developing AD. ${ }^{5}$ Hypoxia is also widely discussed to have a role in the demyelination of axons in $\mathrm{MS}^{6}$ and to decrease the dopaminergic activity. ${ }^{7}$ Finally, hypoxia is known to occur after cell transplantation and to affect eminently the survival of the implanted cells in the first critical posttransplantational phase. Hypoxic preconditioning of stem cells before transplantation may improve the survival and therapeutic effects of implanted cells. ${ }^{8}$ The role of Glu in the pathophysiology of neurodegenerative diseases mostly revolves around its excitotoxic effects as a common mechanism of neuronal damage in $\mathrm{AD}, \mathrm{PD}$, stroke, neurotrauma and $\mathrm{MS}^{9}$ One of the factors known to protect different types of neural cells against both hypoxia- and Glu-induced cytotoxicity is erythropoietin (EPO). Its protective and regenerative effects have been shown for a broad range of neurodegenerative diseases in both experimental and clinical trials; EPO enhances neurogenesis and provides neuroprotection during experimental stroke. ${ }^{10}$ It exerts an anti-inflammatory effect on the central nervous system (CNS) in a model of experimental autoimmune encephalomyelitis ${ }^{11}$ and improves motor function in MS patients. ${ }^{12}$ The ability of EPO to prevent early and late apoptotic neuronal injury during Abeta toxicity in vitro raises the possibility of its therapeutic benefit during AD. ${ }^{13}$ EPO has been recently shown to protect dopaminergic neurons and to improve neurobehavioral outcome in a rat model of PD. ${ }^{14}$ It also abolishes hypoxia-induced death of neuronal progenitors in vitro ${ }^{15}$ and acts synergistically with MSC to potentiate the post-ischemic neurogenesis in a rat model of cerebral ischemia. ${ }^{16}$ Although these findings support a pivotal role of EPO in neuroprotection, the mechanisms of its beneficial influence on therapeutic cells (e.g., MSC) remain unclear. Taking into consideration that MSC engrafted into neurodegenerative tissue will be exposed to hypoxia (either caused by surgery or initially present as a pathogenetic factor of the respective disease) and Glu excess (caused by the disease), in this study we investigated the influence of EPO on the survival, differentiation and protective features of MSC exposed to hypoxia, Glu and Abeta. The results of this study identify EPO as a crucial factor in the specialized cholinergic neuron-like differentiation of MSC, as well as in their acquirement of neuroprotective features such as the glutamate transporter, GLAST, and the glutamate-metabolizing enzyme, glutamine synthetase (GS). This suggests that EPO should be co-administered as a therapeutic agent in a stem cell-based therapy (CBT) of neurodegenerative disorders.

\section{Results}

Human MSC (hMSC) showed adipogenic differentiation (lipid vacuoles stained with oil red $\mathrm{O}$ shown in Figure 1, row a) after treatment for 21 days with adipogenic medium. After treatment for 21 days with osteogenic medium, staining for alkaline phosphatase showed osteogenic differentiation (pink color in Figure 1, row o). A 14-day long treatment with chondrogenic medium resulted in chondrocyte pellets. Alcian blue stained the mucopolysaccharides blue to bluish green (Figure 1, row c).

Under normoxic conditions (NCs), hMSC weakly expressed EPOR (Figure 2a). Most of the cells were positive for $\beta$-tubulin III. Administration of EPO under NCs led to the stronger expression of $\beta$-tubulin III (Figure $2 \mathrm{~b}$ ) and appearance of cells with neuron-like morphology (arrow in Figure 2b). Expression of EPOR was upregulated by hypoxia (Figure 2c). Application of EPO under hypoxic conditions (HCs) led to a most prominent increase in the population of neuron-like cells that formed neurosphere-like clusters and showed a strong expression of $\beta$-tubulin III and EPOR (Figure $2 \mathrm{~d}$ ).

Under normoxia, a small population of hMSC expressed glial fibrillary acidic protein (GFAP; Figure 2e). No changes in the number of GFAP-positive cells were seen in EPO-treated cultures under NC (cf. Figures $2 e$ and f). Hypoxia changed the morphology of GFAP-positive cells: the cells were of a round, undifferentiated shape under $\mathrm{HC}$ in comparison with a polygonal shape under NC (cf. arrows in Figures $2 \mathrm{~g}$ and e).

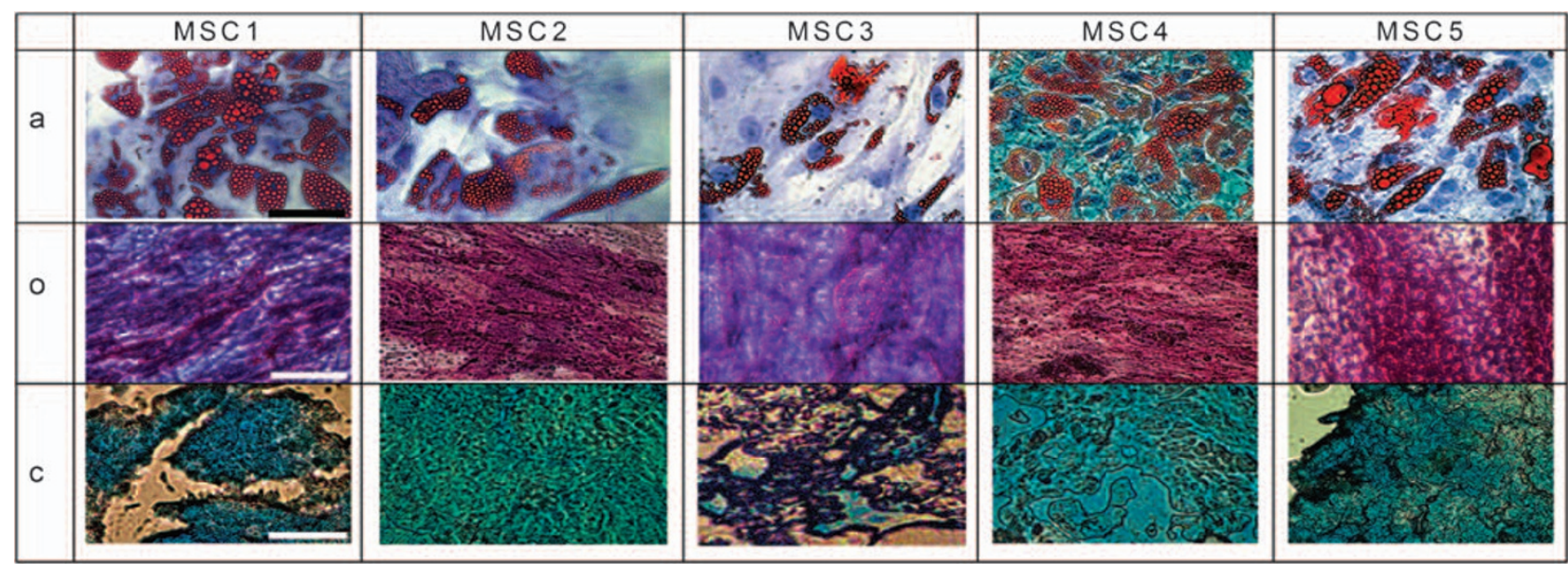

Figure 1 Light microscopy of adipogenically, osteogenically and chondrogenically differentiated adult hMSC from five donors. a: Adipogenic differentiation after 21 days of treatment with adipogenic medium. Staining with oil red $\mathrm{O}$ and hematoxylin counterstaining (scale bar: $100 \mu \mathrm{m}$ ). Red droplets represent lipid vacuoles. 0 : Osteogenic differentiation after 21 days of treatment with osteogenic medium. Staining for alkaline phosphatase and hematoxylin counterstaining (scale bar: $50 \mu \mathrm{m}$ ). Positive cells are stained pink to violet. c: Chondrogenic differentiation after 14 days of treatment with chondrogenic medium. Mucopolysaccharides are stained blue to bluish green (scale bar: $50 \mu \mathrm{m}$ ) 

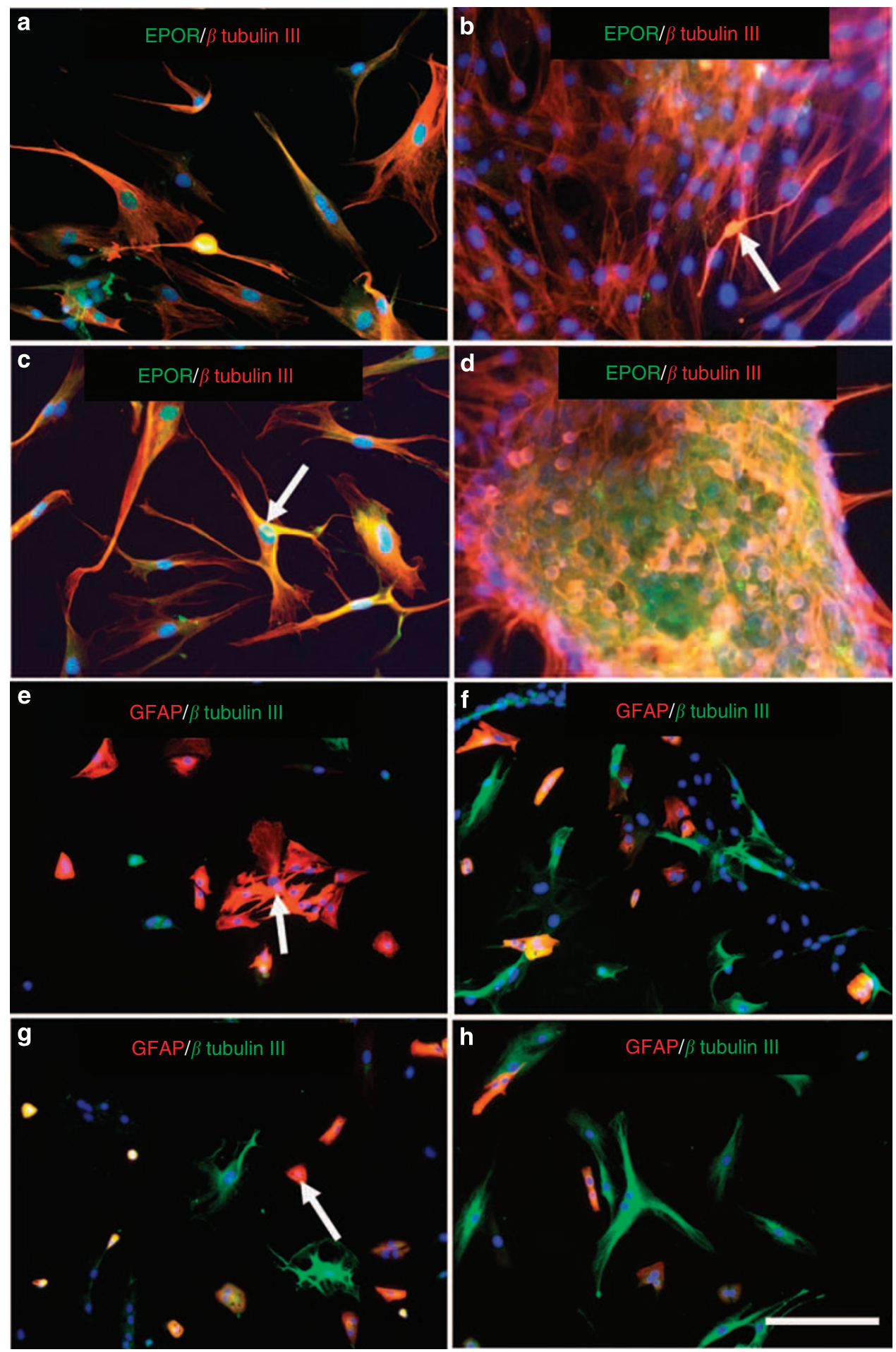

Figure 2 Expression of EPOR, $\beta$-tubulin III and GFAP in hMSC under normoxic and hypoxic conditions. EPOR (green in a-d) weakly expressed in normoxic control cultures (a) and EPO-treated hMSC under normoxia (b) was upregulated in hypoxic controls (c). The level of EPOR expression under hypoxia was not affected by EPO treatment (d). $\beta$-tubulin III (red in a-d, green in $\mathbf{e - f}$ ) was expressed by the majority of cells in normoxic (a) and hypoxic controls (c), especially those expressing EPOR (arrow in c). Cells treated with EPO under normoxia developed a neuron-like morphology (arrow in $\mathbf{b}$ ). EPO strongly increased the population of $\beta$-tubulin IIIpositive, neuron-like cells under hypoxic culture conditions (d). Only a small subpopulation of hMSC expressed GFAP in all culture conditions analyzed (red in e-h). EPO decreased the number of GFAP-positive cells upon hypoxic $(\mathbf{h})$ but not normoxic $(\mathbf{f})$ conditions in comparison with the respective normoxic (e) and hypoxic (g) controls. GFAPpositive cells possessed polygonal shapes under normoxia (arrow in e), but round shapes under hypoxia (arrow in f). The cell nuclei were stained with DAPI (blue). Scale bar: $100 \mu \mathrm{m}$ 
EPO-treated cells under $\mathrm{HC}$ expressed less GFAP than those in the corresponding $\mathrm{HC}$ control (cf. Figure $2 \mathrm{~h}$ versus Figure 2g).
Analysis of EPO and GS expression in hMSC showed an intense staining for endogenously produced EPO in cells strongly expressing GS under NC (arrow in Figure 3a).
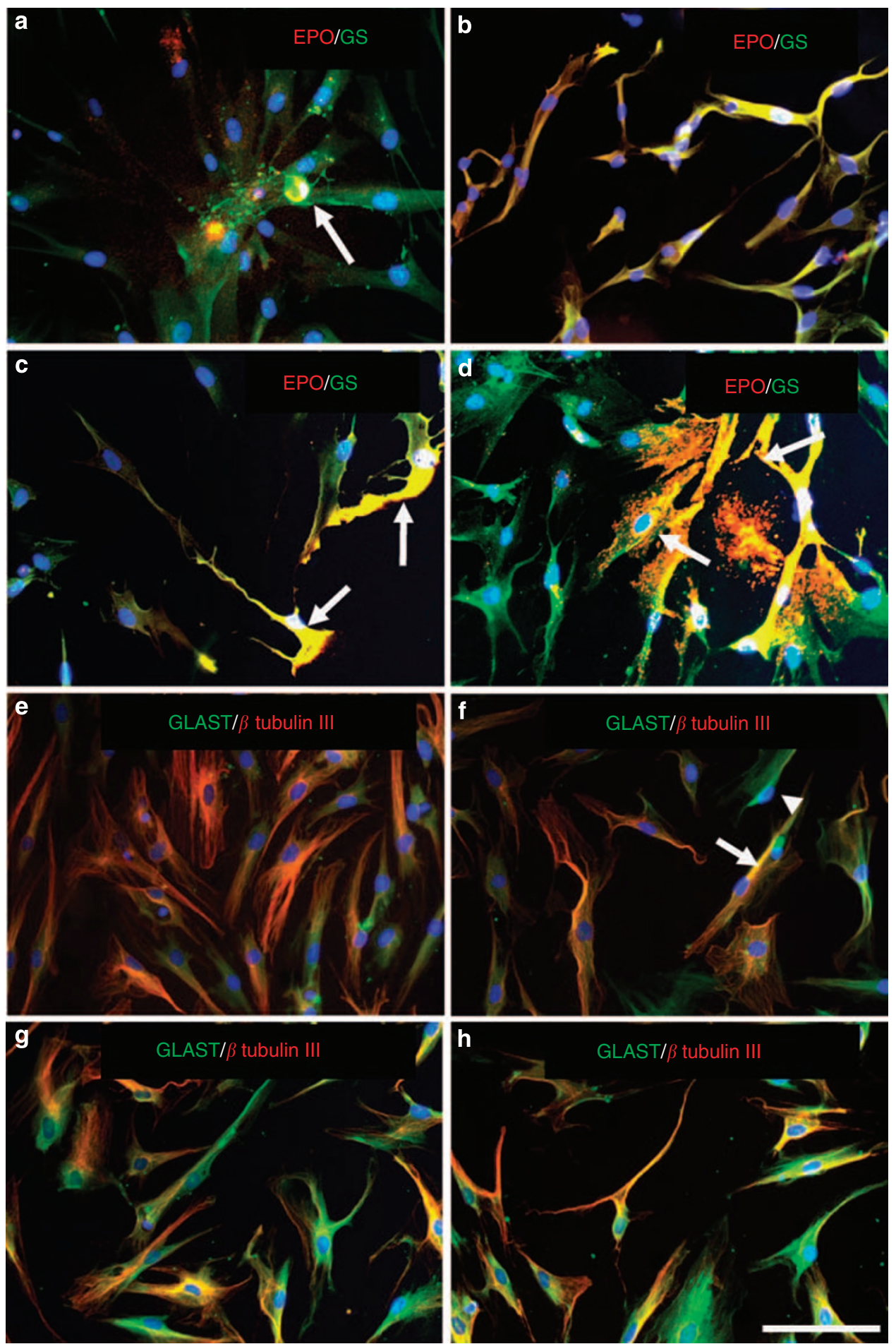

Figure 3 Influence of hypoxia and EPO on the Glu-metabolizing phenotype of hMSC. Strong expression of GS (green in a-d) coexisted with an intense staining for EPO (red in a-d) endogenously expressed under normoxic (arrow in a) and hypoxic (arrows in c) control conditions shown by intense yellow staining of cells. After application of EPO upon normoxia (b) and hypoxia (d), the majority of cells expressed GS. The most intense staining of GS was seen in EPO-positive cells (arrows in d). GLAST (green in $\mathbf{e}-\mathbf{h}$ ) was weakly expressed in $\beta$-tubulin III-positive cells in the normoxic control (e) and was slightly upregulated by EPO under normoxia (f). Hypoxia increased the number of GLAST-positive cells (g). The most intense staining of GLAST is seen in EPO-treated cultures upon hypoxia (h). The cell nuclei were stained with DAPI (blue). Scale bar: $100 \mu \mathrm{m}$ 
Application of EPO under NC increased the population of cells positive for EPO, indicating the uptake of exogenously applied EPO by hMSC (Figure 3b). These cells revealed a strong expression of GS reflected by intense yellow staining resulting from merged green (GS) and red fluorescence (EPO) in Figure 3b.

Hypoxia enhanced the endogenous expression of EPO in cells strongly positive for GS (arrows in Figure 3c). Application of EPO under $\mathrm{HC}$ resulted in an increase of GS staining in a majority of the cells (Figure $3 d$ ), with a most intense staining in cells strongly positive for EPO (arrows in Figure 3d).

A weak expression of GLAST (green in Figures $3 e-h$ ) was seen in cultures under NC (Figures $3 e$ and f). GLAST was expressed in both $\beta$-tubulin III-positive MSCs (arrow in Figure 3f) and cells lacking $\beta$-tubulin III (arrowhead in Figure 3f). Hypoxia slightly increased the expression of GLAST in hMSC (Figure $3 \mathrm{~g}$ ), although the most intense staining for GLAST was observed in cultures exposed to EPO under hypoxia (Figure 3h).

Glutamate decreased the viability of hMSC under NC reflected by an increased lactate dehydrogenase (LDH) release from hMSC in comparison with a NC control without Glu (Figure 4a). Both preincubation of cells with EPO before exposure to Glu and co-administration of EPO and Glu under NC diminished the release of LDH (Figure 4a). Exposure to Glu under hypoxia showed a higher increase in LDH levels than the one seen under NC (cf. $+G$ in Figure $4 b$ with $+G$ in Figure 4a). EPO given before or simultaneously with Glu was capable of increasing the viability of hMSCs to the levels of the hypoxic control without Glu (Figure 4b).

Under NC, cells exposed to Glu showed a higher activity of GS, when compared with samples incubated without Glu (Figure 4c). Application of EPO before the exposure of the cells to Glu or simultaneously with Glu led to a significant increase in GS activity under NCs. Here, cells preincubated with EPO before exposure to Glu did not reveal higher levels of GS activity in comparison with those incubated with EPO and Glu simultaneously (Figure 4c). Addition of $1 \mathrm{mM}$ Glu under hypoxia did not change the activity of GS, whereas EPO, either preincubated or applied simultaneously with hypoxia and Glu, significantly increased the GS activity of hMSC (Figure 4d).

Immunofluorescence analysis revealed a weak perinuclear expression of synaptophysin in hMSC under NCs (Figure 5a). The cells exposed to EPO under NC possessed synaptophysin in cell bodies and processes (Figure $5 b$ ) and were also positive for $\beta$-tubulin III (arrows in Figure 5b). HMSC exposed to hypoxia revealed a higher expression of synaptophysin compared with that in the NC (Figure 5c), whereas the application of EPO under HC appeared to induce the formation of vesicles containing synaptophysin in the area of contact between the cells (arrowheads in Figure $5 \mathrm{~d}$ ).

The quantification of acetylcholine (ACh) in the culture supernatant of hMSC showed that Glu reduces the production/release of ACh in hMSC in comparison with the NC (Figure 5e), whereas EPO applied simultaneously with Glu restored the production of $\mathrm{ACh}$ to the levels of the NC-control (Figure 5e). Exposure of hMSC cultures to the soluble cysteine-rich domain (CRD) of Fzd7, a functional antagonist of Wnt3a, ${ }^{17}$ abolished the effect of EPO on the release of ACh
(Figure 5e). Similar to the co-administration with EPO, CRD Fzd7 applied alone decreased the ACh down to the level of the control treated with Glu (Figure 5e).

The assessment of apoptosis in hMSC cultures by quantification of TUNEL-positive cells revealed a strong anti-apoptotic effect of EPO. EPO prominently decreased the number of TUNEL-positive cells upon normoxia (Figure $5 f$, cf. $\mathrm{N}$ versus $\mathrm{N}+\mathrm{EPO}$ ), hypoxia (Figure $5 \mathrm{f}$, cf. $\mathrm{H}$ versus $\mathrm{H}+\mathrm{EPO}$ ) and exposure to Glu under both $\mathrm{NC}$ and $\mathrm{HC}$ (Figure $5 f$, cf. $\mathrm{N}+\mathrm{G}$ versus $\mathrm{N}+\mathrm{G}+\mathrm{EPO}$ and $\mathrm{H}+\mathrm{G}$ versus $\mathrm{H}+\mathrm{G}+\mathrm{EPO})$. However, EPO could not decrease the number of apoptotic cells if combined with CRD Fzd7. In fact, under this condition the number of TUNEL-positive cells was almost eightfold higher than in the respective normoxic or hypoxic controls (Figure $5 f$, cf. $\mathrm{N}$ versus $\mathrm{N}+\mathrm{EPO}+\mathrm{CRD} \mathrm{Fzd} 7$ and $\mathrm{H}$ versus $\mathrm{H}+\mathrm{EPO}+\mathrm{CRD} \mathrm{Fzd7}$ ). The number of TUNELpositive cells was also dramatically increased in the presence of CRD Fzd7 applied alone (Figure $5 f$, cf. $\mathrm{N}$ versus $\mathrm{N}+\mathrm{CRD}$ $\mathrm{Fzd} 7$ and $\mathrm{H}$ versus $\mathrm{H}+\mathrm{CRD} \mathrm{Fzd} 7$ ).

Exposure of hMSC to EPO under NC led to an increase in the number of neuronal nuclei-specific protein (NeuN)positive cells (cf. Figures $6 a$ and $b$ and $N$ versus $N+E$ in Figure 6e). Hypoxia did not lead to significant changes in the number of NeuN-positive hMSC (Figures $6 \mathrm{a}$ and $\mathrm{c}, \mathrm{N}$ versus $\mathrm{H}$ in Figure 6e). EPO applied under HC considerably increased the population of NeuN-positive hMSC (Figure 6c versus Figure $6 \mathrm{~d}$ ). The number of cells was even higher than that in normoxic control cultures (cf. $\mathrm{H}+\mathrm{E}$ with $\mathrm{H}$ and $\mathrm{N}$ in Figure $6 \mathrm{e}$ ). To prove that the increase in the number of NeuN-positive hMSC cannot simply be explained by the increase in the total number of cells under $\mathrm{NC}$ and $\mathrm{HC}$ conditions, either due to a proliferative effect of EPO or by its survival-increasing effect under hypoxia, we counted the total cell number by the quantification of nuclei stained with $4^{\prime}, 6$ diamidino-2-phenylindole (DAPI). Neither under NC nor under $\mathrm{HC}$ could a change in cell number be observed after application of EPO (Figure 6f).

Further analyses have shown that EPO is capable of: (i) enhancing the expression of synaptophysin, ChAT, leukemiainhibitory factor (LIF), GLAST, neprilysin, Wnt3a, $\beta$-catenin (Figure 7 and Table 1), M1-M3R and $\beta$-tubulin III (Figure 8); (ii) increasing the response of MSC to ACh shown by a transient increase in intracellular $\mathrm{Ca}^{2+}$ (Figure 9); (iii) decreasing the Abeta-induced release of IL- 6 from MSC; and (iv) increasing the Abeta-degrading function of MSC in the presence of APPsw-PC12 cells (Figure 10). For the detailed explanation of the data shown in Figures 7-10 and Table 1 see supplementary information online.

\section{Discussion}

The data shown here reflect a strong capacity of EPO to induce neurogenic differentiation of hMSC, which is potentiated by simultaneous exposure of the cells to hypoxia. A prominent increase in expression of numerous neuronal markers ( $\beta$-tubulin III, NeuN, ChAT, muscarinic M1R, M2R and M3R) was observed after treatment with EPO under both normoxic and, especially, hypoxic conditions. EPO also increased the generation of vesicles containing synaptophysin. The synergistic effect of hypoxia and EPO on the 
Normoxia

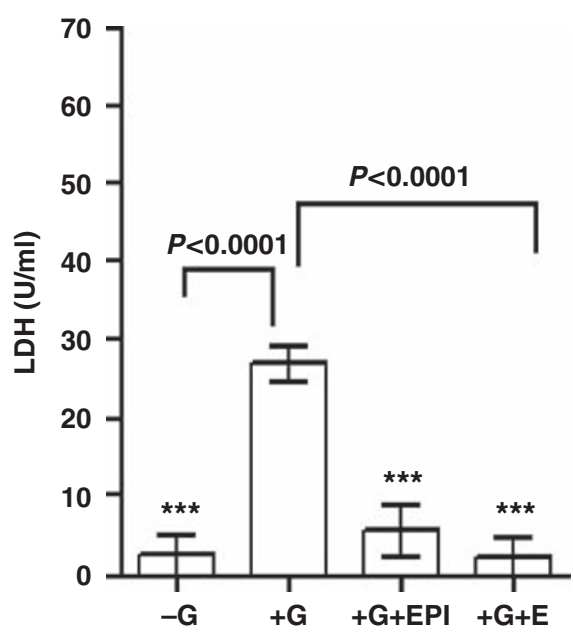

C

Normoxia

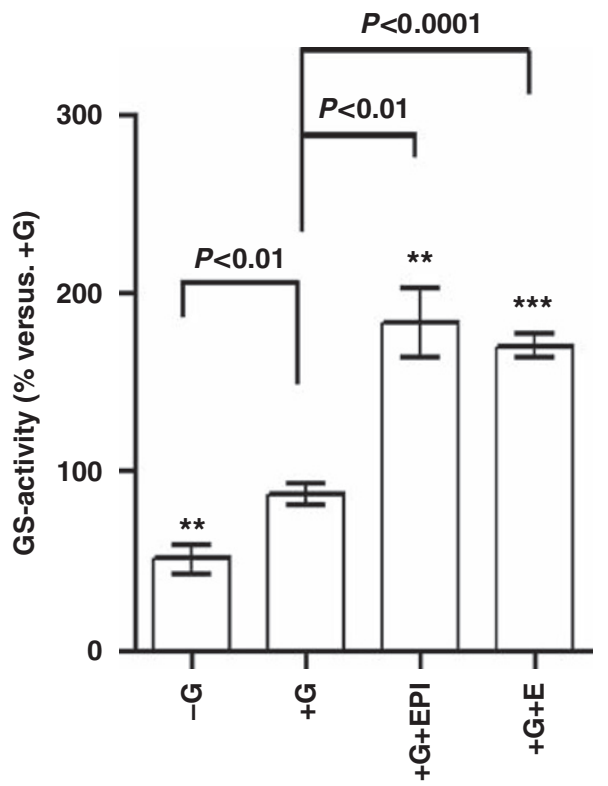

b
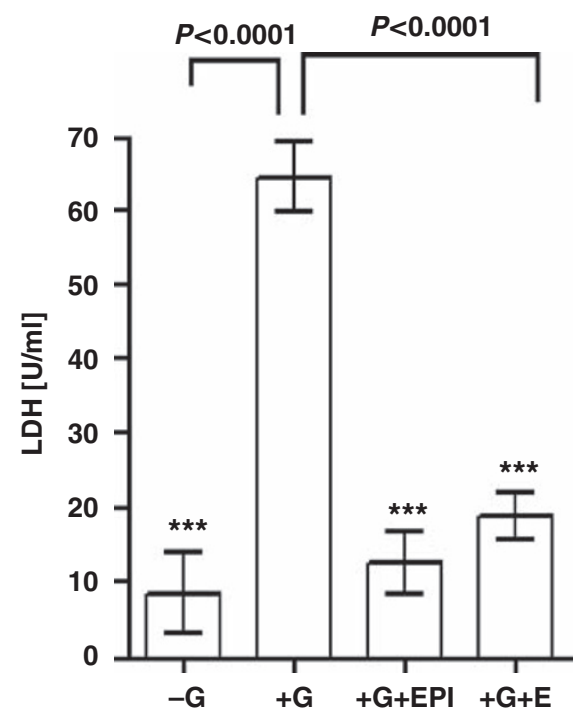

d

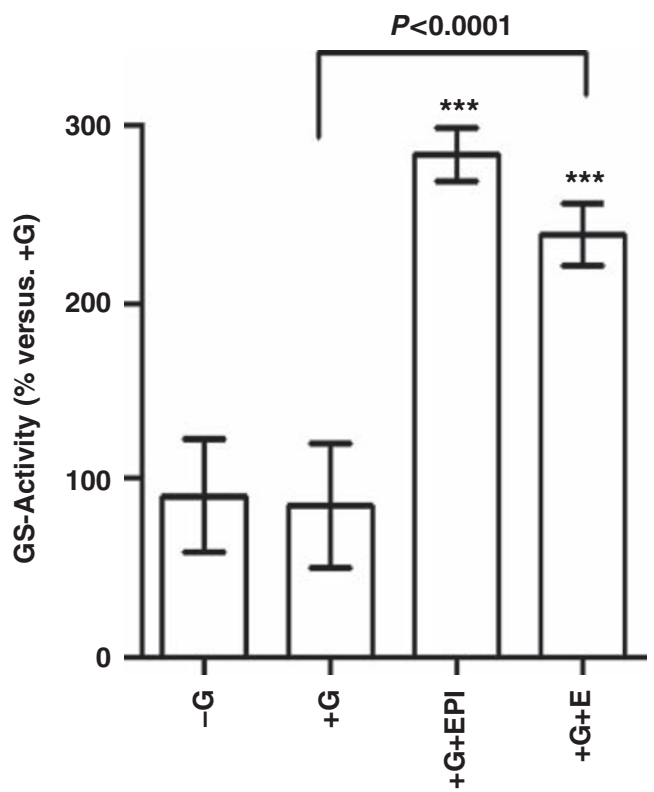

Figure 4 LDH-release and GS activity of human MSC (hMSC) under hypoxia and Glu exposure. HMSCs were cultured for $48 \mathrm{~h}$ under normoxic or hypoxic conditions and/ or exposure to $1 \mathrm{mM} \mathrm{Glu}$. Under normoxic conditions $(\mathbf{a}), 1 \mathrm{mM}$ Glu increased the $\mathrm{LDH}$ release from cells into the culture supernatant $(+\mathrm{G})$ as compared with the control without Glu $(-\mathrm{G})$. EPO applied simultaneously $(+\mathrm{G}+\mathrm{E})$ or $24 \mathrm{~h}$ before exposure of the cultures to $1 \mathrm{mM} \mathrm{Glu}(+\mathrm{G}+\mathrm{EPI})$ significantly decreased the LDH release from cells in comparison with the control exposed to Glu $(+\mathbf{G})$. Hypoxia (b) potentiated the toxic effect of Glu on hMSC, as reflected by more LDH activity in the culture supernatant $(+G)$ compared with the control without Glu $(-G)$. A comparison of $+G$ normoxia (a) with $+G$ hypoxia $(\mathbf{b})$ also reveals a highly significant difference as a consequence of Glu toxicity (2.4-fold increase of LDH under hypoxia, $P<0.0001)$. EPO either co-administered with Glu $(+G+E)$ or preincubated $(+G+E P I)$ with the cells before $G$ lu exposure strongly reduced the LDH-release under hypoxia. Glu $(1 \mathrm{mM})$ induced $\mathrm{GS}$ activity in $\mathrm{hMSC}$ under normoxic conditions $(\mathbf{c},+\mathrm{G})$ in comparison with control cultures without exposure to $\mathrm{Glu}(\mathbf{c},-\mathrm{G}$ ). Hypoxia (d) disabled hMSC in their capacity to upregulate their GS activity in response to $1 \mathrm{mM}$ Glu (no difference between $-\mathrm{G}$ and $+\mathrm{G}$ in $\mathbf{d}$ ). EPO applied simultaneously with exposure of cells to Glu $(+\mathrm{G}+\mathrm{E})$ under normoxic $(\mathbf{c})$ and hypoxic (d) conditions enhanced the GS activity. Pretreatment of cultures with EPO did not cause an additional increase in GS activity. The data are shown as percentages (mean \pm S.E.M.) of the respective controls under normoxia (c, $+G$ ) and hypoxia $(\mathrm{d},+\mathrm{G})$. One-way ANOVA with Bonferroni's comparison was used for multiple comparisons between controls and treated samples $\left({ }^{\star \star \star} P<0.0001,{ }^{\star \star} P<0.001\right)$

upregulation of neuronal ( $\beta$-tubulin III, NeuN, ChAT, muscarinic M1R, M2R and M3R) and functional markers (GLAST, neprilysin) can be explained by increased EPOR synthesis in MSC under HCs. The upregulation of EPOR shown here is concordant with the report of Zwezdaryk et al. ${ }^{18}$ showing the hypoxia-induced upregulation of EPOR in hMSC. EPO seems to induce neuron-like differentiation of hMSC acting synergistically with hypoxia, and at the same time may restrict glia-like 

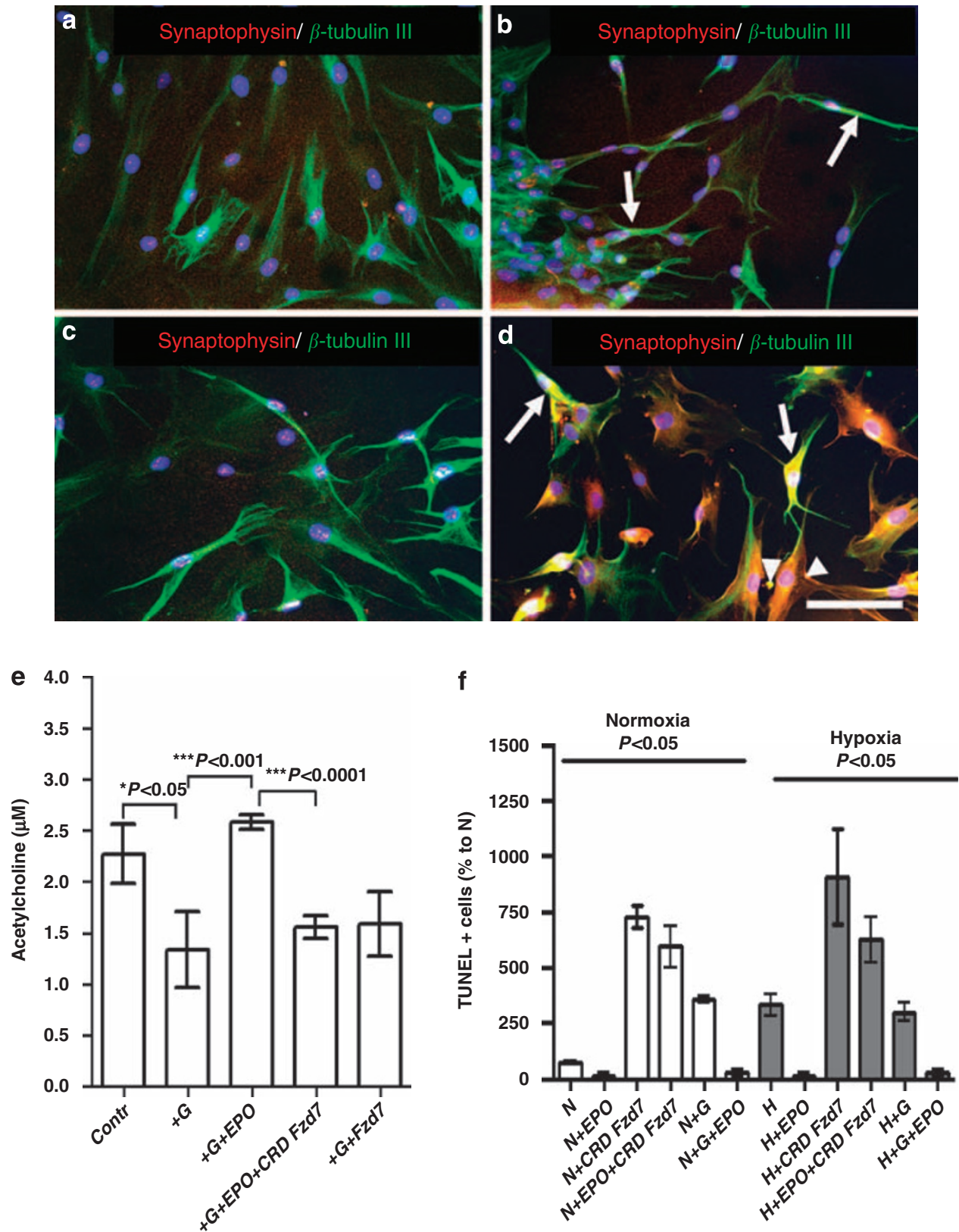

Figure 5 Detection of synaptophysin, ACh and DNA ends (TUNEL) in hMSC upon hypoxia and EPO-treatment. Synaptophysin (red in a-d) was weakly expressed by $\beta$-tubulin III-positive cells (green throughout a-d) under normoxic control conditions (a). A slight increase in a population of synaptophysin-positive cells was seen under EPO treatment under normoxia (arrows in b). Hypoxia (48 h) slightly increased the synaptophysin expression (c). EPO applied under hypoxic conditions led to the formation of vesicles containing synaptophysin (arrowheads in d). The cell nuclei were stained with DAPI (blue). Scale bar: $100 \mu \mathrm{m}$. Acetylcholine (panel e) was detected in the cell culture supernatant of hMSC cultured under normoxia and exposed to glutamate (Glu) for $48 \mathrm{~h}$. The antagonist of Wnt3a signaling, CRD Fzd7, was applied at $1 \mathrm{~h}$ before the application of EPO and Glu ( $1 \mathrm{mM})$. Glu ( $+G$ in e) reduced the release of ACh in hMSC (cf. control with $+G$ in $e, P<0.03$ ), whereas the application of EPO to Glu-exposed cultures enhanced the levels of $A C h$ (cf. $+G$ versus $+G+E P O, P<0.001$ in e). CRD Fzd 7 abolished their effect of $E P O$ (cf. $+G+E P O$ with $+G+E P O+C R D$ Fzd7, $P<0.0001$ in e). The data are shown as mean \pm S.E.M. One-way ANOVA with Bonferroni's comparison was used for multiple comparisons between controls and treated samples. Quantification of TUNEL + cell was performed in hMSC cultures exposed to hypoxia (48 h), $1 \mathrm{mM}$ Glu and CRD Fzd7 (preincubated for $1 \mathrm{~h}$ before the application of EPO). The data are shown in percentages (mean \pm S.E.M.) of the normoxic control ( $\mathrm{N}$ in panel $\mathrm{f})$. One-way ANOVA with Bonferroni's comparison was used for multiple comparisons between control and treated samples $\left({ }^{* \star *} P<0.0001,{ }^{* \star} P<0.001\right)$

differentiation of MSC. The decrease in the number of GFAPpositive cells under hypoxia and EPO administration cannot be simply explained by cellular death, as EPO has been shown to protect hMSC from hypoxia-induced cell death and/ or Glu toxicity (shown by TUNEL quantification). Here we also show that hMSC produce GS, the activity of which seems to be upregulated by EPO. In the CNS, GS is physiologically produced by astrocytes and has a pivotal role in the 

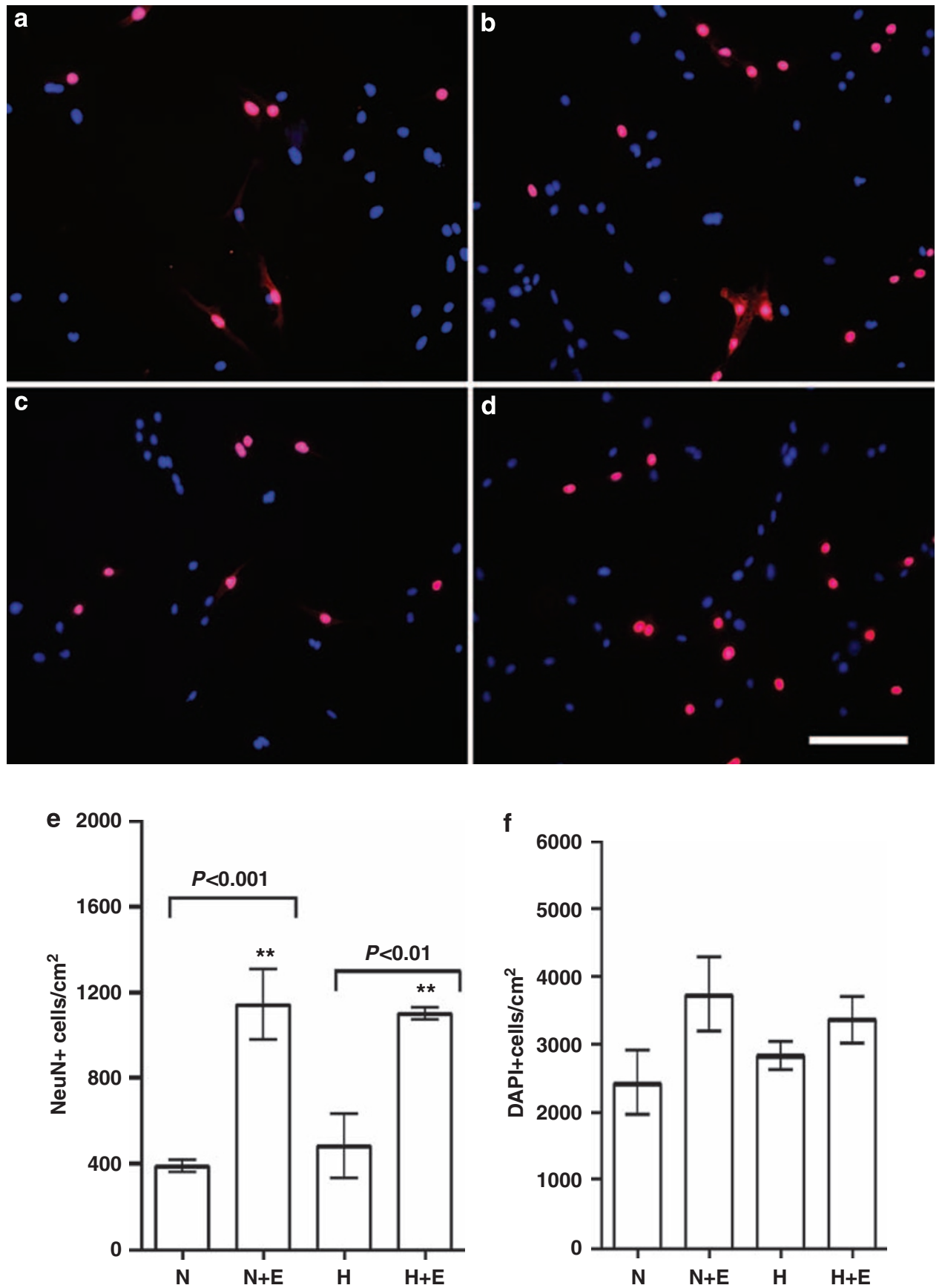

Figure 6 NeuN-positive population of hMSC under hypoxia and treatment of EPO. NeuN-positive cells (red and pink staining resulting from merged bluish DAPI and red NeuN staining) were detected under normoxic (a) and hypoxic (c) control conditions. Treatment with EPO increased the number of NeuN-positive cells under normoxic (b) and hypoxic (d) condition. Scale bar: $100 \mu \mathrm{m}$. Quantification of NeuN-positive hMSC (e) revealed an increase in the number of NeuN-positive cells in cultures supplemented with EPO under normoxic $(\mathrm{N}+\mathrm{E})$ and hypoxic $(\mathrm{H}+\mathrm{E})$ conditions in comparison with the respective controls $(\mathrm{N}$ and $\mathrm{H})$. The total amount of cells evaluated by quantification of DAPI-positive cells remained unchanged either after exposure of cells to hypoxia or application of EPO (f). Data presented as mean \pm S.E.M. were analyzed by Student's $t$-test comparing each treated sample with its respective control

glutamine-glutamate cycle. This cycle assures the removal of excitotoxic concentrations of Glu from the extracellular space and therefore the survival of neurons. However, under pathological conditions such as ischemia and $A D$, astrocytes are hampered in their capacity to produce GS, whereas neurons start to synthesize this enzyme. ${ }^{19} \mathrm{HMSC}$ exposed to hypoxia failed to respond to $1 \mathrm{mM}$ Glu with an increase in GS activity, reflecting the inability of hMSC to survive and maintain their Glu-metabolizing function on simultaneous exposure to hypoxia and Glu. EPO decreased LDH release from hMSC down to the levels of the respective hypoxic but Glu-free control and induced GS activity. It has been shown 
Table 1 Densitometric values of proteins analyzed in hMSC by western blot shown in Figure 7

\begin{tabular}{|c|c|c|c|c|c|c|c|c|}
\hline \multirow[b]{3}{*}{ Protein } & \multirow[b]{3}{*}{$\mathbf{N}$} & \multicolumn{7}{|c|}{ Condition } \\
\hline & & N+EPO & $\mathrm{N}+\mathrm{CRD}$ Fzd7 & N+EPO+CRD Fzd7 & $\mathbf{H}$ & H+EPO & H+CRD Fzd7 & H+EPO+ CRD Fzd7 \\
\hline & & \multicolumn{7}{|c|}{$\%$ to normoxic control (N) } \\
\hline Synaptophysin & 100 & 324 & 171 & 160 & 299 & 498 & 291 & 334 \\
\hline ChAT & 100 & 169 & 34 & 47 & 156 & 226 & 22 & 52 \\
\hline LIF & 100 & 194 & 105 & 149 & 193 & 246 & 206 & 176 \\
\hline EPOR & 100 & 135 & 111 & 122 & 223 & 119 & 104 & 72 \\
\hline GFAP & 100 & 109 & 254 & 257 & 237 & 168 & 216 & 156 \\
\hline GLAST & 100 & 259 & 84 & 110 & 142 & 223 & 63 & 77 \\
\hline Neprilysin & 100 & 148 & 37 & 52 & 92 & 161 & 54 & 88 \\
\hline Wnt3a & 100 & 169 & 49 & 95 & 348 & 510 & 51 & 41 \\
\hline$\beta$-catenin & 100 & 93 & 72 & 80.7 & 59 & 97 & 45 & 71 \\
\hline
\end{tabular}

The values are indicated in $\%$ of the respective normoxic control value of each target protein

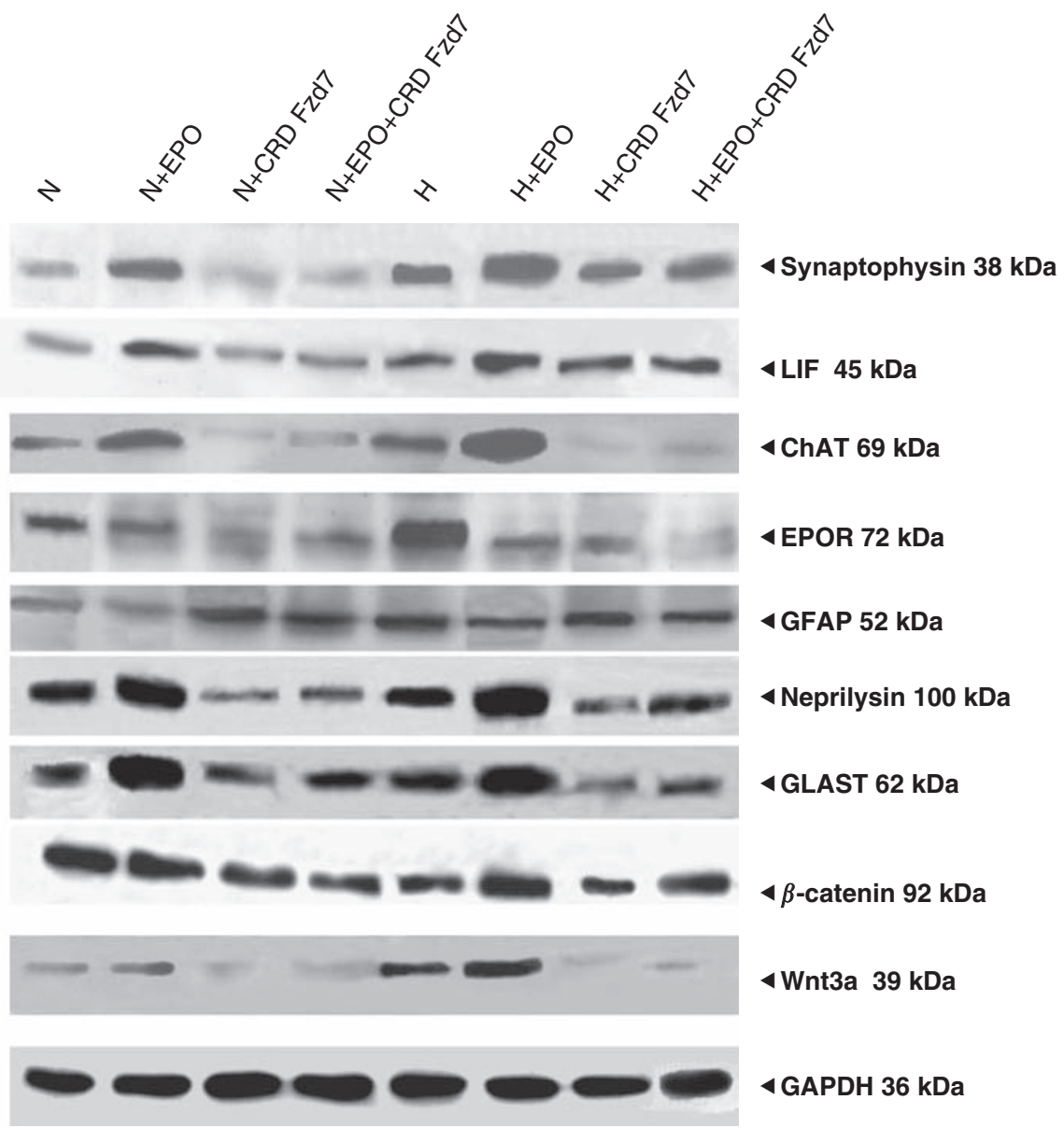

Figure 7 Western blot analysis of Wnt3a, $\beta$-catenin, neprilysin, LIF, GLAST, glial and synaptic markers in hMSC upon hypoxia and EPO treatment. Samples from normoxic $(\mathrm{N})$ and hypoxic $(\mathrm{H})$ controls, from EPO-treated cultures $(\mathrm{N}+\mathrm{E}$ and $\mathrm{H}+\mathrm{E})$ and from cultures treated with EPO in the presence of CRD Fzd7 (N + EPO + CRD Fzd7 and $\mathrm{H}+\mathrm{EPO}+\mathrm{CRD}$ Fzd 7) were analyzed for the presence of synaptophysin, LIF, ChAT, EPOR, GFAP, neprilysin, GLAST, $\beta$-catenin and Wnt3a. GAPDH was used as a loading control

previously that in vitro, MSC express GS and the Glu transporters GLAST and GLT-1, ${ }^{20}$ indicating that these cells may be able to take over the Glu-metabolizing function of astrocytes. Our data confirm that MSC do not only produce the active enzyme (GS) and GLAST, but they can also effectively take up Glu in vitro (unpublished results). We also show that without EPO hMSC exposed to hypoxia cannot increase their GS activity in response to Glu excess, whereas EPO can induce GS activity and the expression of GLAST in hMSC under these toxic conditions. The importance for in vivo 
a

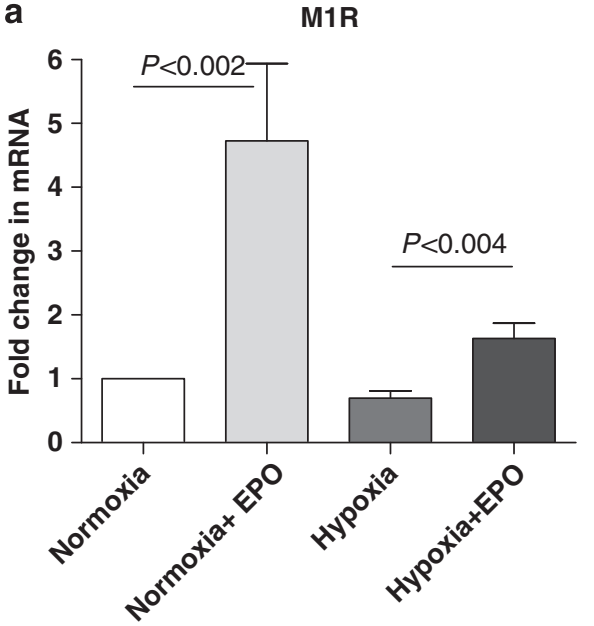

C

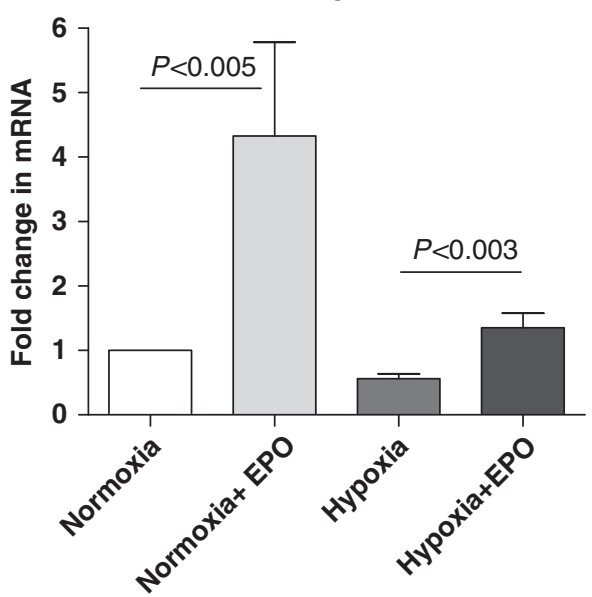

b

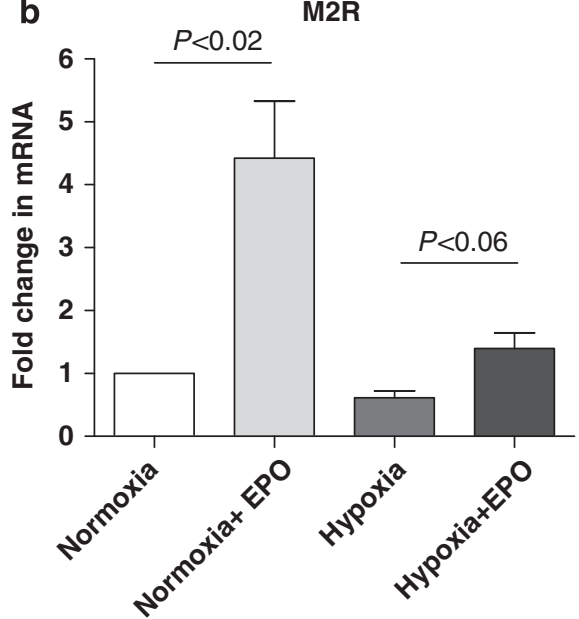

d NGF

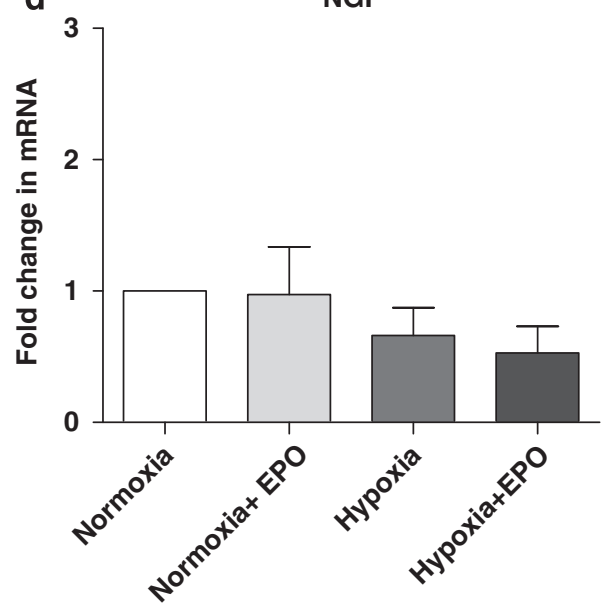

e

$\beta$-tubulin III

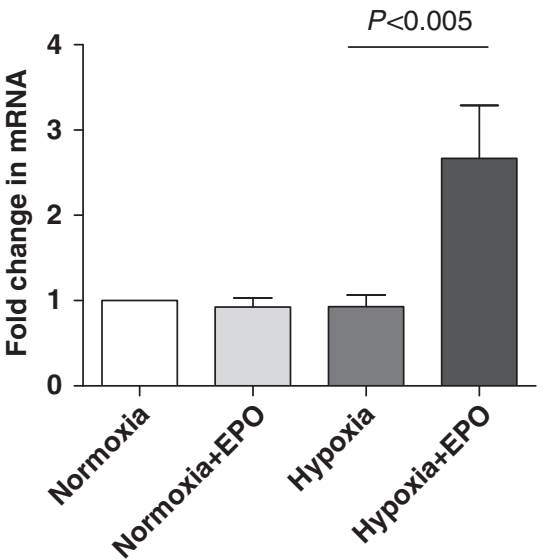

Figure 8 mRNA levels for muscarinic receptors, NGF and $\beta$-tubulin III in hMSC. Levels of the mRNAs for muscarinic receptors M1R (a), M2R (b), M3R (c) and of NGF (d) in hMCS were measured by qPCR. $\Delta \mathrm{C}_{\mathrm{T}}$ values for each transcript under the indicated conditions were calculated relative to the respective $\beta_{2}$-microglobulin transcript level (housekeeping transcript), and fold changes in $\mathrm{C}_{\mathrm{T}}$ values $\left(\Delta \Delta \mathrm{C}_{\mathrm{T}}\right.$ values) were computed in relation to cells cultivated under normoxic conditions. The mean $\mathrm{C}_{\mathrm{T}}$ of the $\beta_{2}$-microglobulin transcript was $18.15 \pm 0.68$ and no differences in this value between culture conditions were seen. The change in $\beta$-tubulin III mRNA level was calculated with respect to the mean of the normoxic control (e). The means of five readings of independent samples are shown \pm S.E.M. The experiment was carried out in duplicate. Student's t-test was used to compare values with their respective controls (normoxic versus hypoxic conditions) 


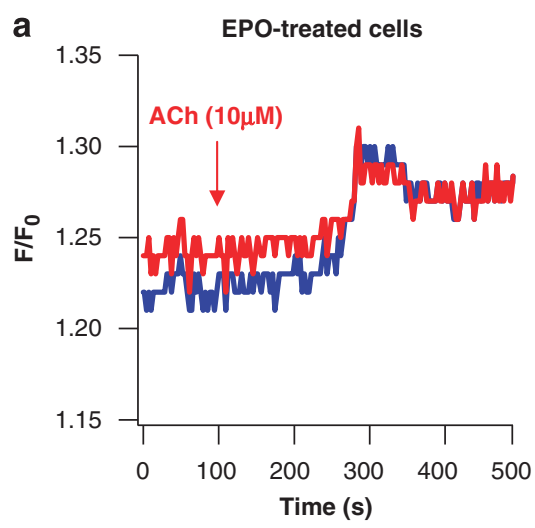

C

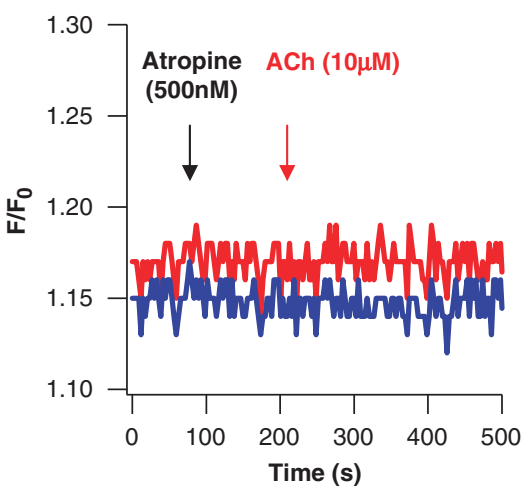

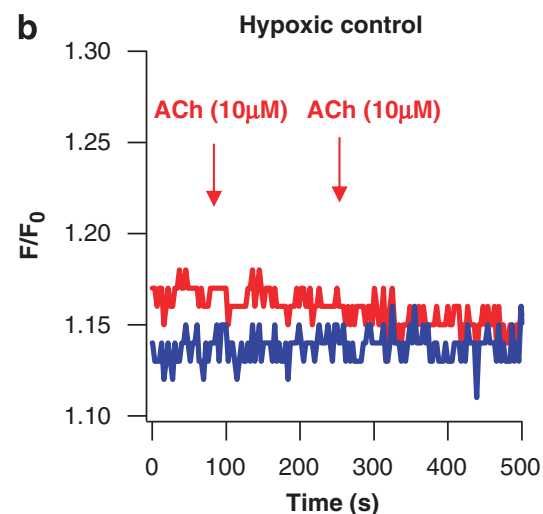

d

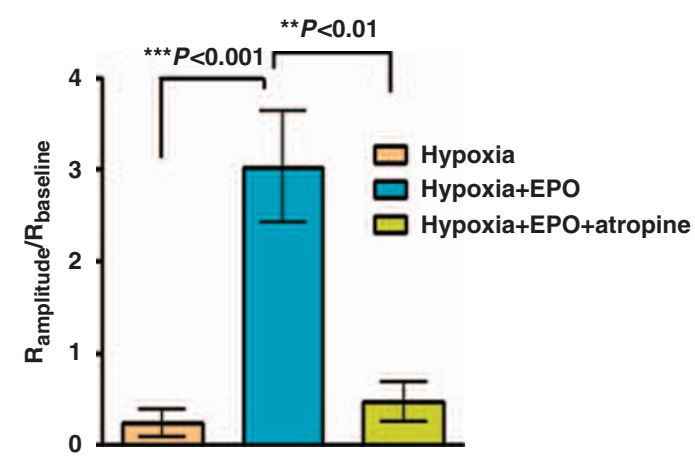

Figure 9 Intracellular $\mathrm{Ca}^{2+}$ transients in hMSC induced by ACh upon hypoxia and application of EPO. Fura-2-loaded hMSC treated with EPO (a and c) and from hypoxic controls (b) were exposed to $\mathrm{ACh}(10 \mu \mathrm{M}$ for $30 \mathrm{~s})$ in calcium-imaging experiments ( $F / F_{0}$ in a-c is the ratio of Fura-2 fluorescence at 353 and $390 \mathrm{~nm}$ ). The majority of cells (two representative measurements out of 16 in total, each colored trace represents the calcium signal of a single cell) treated with EPO upon hypoxia responded to ACh with an increase in their cytosolic $\mathrm{Ca}^{2+}$ concentration (a). MSC from control cultures exposed to hypoxia showed a strongly reduced functionality of muscarinic receptors reflected by unaltered cytosolic $\mathrm{Ca}^{2+}$ levels after stimulation with ACh (b). In control experiments, atropine was used to block the effect of muscarinic receptors in EPO-treated cells (c). Comparison of the amplitude ratios (the ratio of the $\mathrm{Ca}^{2+}$ level amplitude after stimulation with ACh was correlated to the ratio of the baseline $\mathrm{Ca}^{2+}$ level measured immediately before the application of $A C h, R_{\text {amplitude }} / R_{\text {baseline}}$ ) shows a significantly higher $\mathrm{Ca}^{2+}$ level amplitude after stimulation with ACh in EPO-treated cells (d, hypoxia + EPO) in comparison with the hypoxic (d, hypoxia) and the atropine-treated control (d, hypoxia + EPO + atropine)

transplantations of the ability of cultured differentiated MSC to maintain their phenotype and functionality under HCs prevalent in neurodegenerative disorders becomes clear when one considers the organ-specific values for oxygen partial pressure $\left(\mathrm{pO}_{2}\right)$, a major trigger for systemic EPO release (Table 2). The $\mathrm{pO}_{2}$ levels vary considerably between the compartments alveoli, blood and the individual tissues. ${ }^{21-23}$ As confirmed by our study, low $\mathrm{pO}_{2}$ has been shown to promote neurogenic differentiation of MSC. However, despite its capacity to induce neurogenic differentiation, the relatively low $\mathrm{pO}_{2}$ in the brain (in comparison with $\mathrm{BM}$ ) can reduce the protective capacities of MSC and their survival. This negative effect of the low brain $\mathrm{pO}_{2}$ on MSC can be further potentiated by a transplantation procedure or by neurodegenerative disorders accompanied by brain hypoxia.

$A D$ is characterized by progressive loss of cognition, reduction of ACh and ChAT levels, as well as by loss of cholinergic innervation in the CNS. Muscarinic acetylcholine receptors are known to have a key role in the processes of cognition. Impairment of muscarinic receptor signaling (especially through $\mathrm{M} 1 \mathrm{R}$ ) is directly involved in the pathology of
Alzheimer's-like disorders. ${ }^{24}$ Moreover, M1R has a prominent role in the amyloidogenic processing of amyloid precursor protein (APP). ${ }^{25} \mathrm{~A} C \mathrm{CBT}$ in $\mathrm{AD}$ will therefore be aimed at replacing damaged or lost cholinergic neurons to improve cholinergic signal transduction in the host CNS tissue. The involvement of hypoxia in AD pathology is widely discussed in recent reports. It is even proposed that mild or moderate $A D$ may be a toxic manifestation of a primarily hypoxic disease. ${ }^{26}$ Our data show an EPO-induced increase in production of ACh as well as expression of ChAT, M1R, M2R and M3R in hMSC. The functionality of muscarinic receptors reflected by their responsiveness to $\mathrm{ACh}$ and mediation of an increase in cytosolic $\mathrm{Ca}^{2+}$ seems to be positively affected by EPO under HCs. Expression of functional M2 receptors in MSC under NCs was reported recently by Hoogduijn et al. ${ }^{27}$ However, besides detection of $\mathrm{M} 2$ receptor mRNA, these authors showed that none of the other muscarinic receptor types (M1, M3-5) could be detected on the mRNA level. Here we show an upregulation of $\mathrm{M} 1-\mathrm{M} 3$ receptors at the mRNA level in hMSC treated with EPO upon normoxia and hypoxia. The functional activity of $\mathrm{M} 1, \mathrm{M} 3$ and $\mathrm{M} 5$ receptors reflected by 

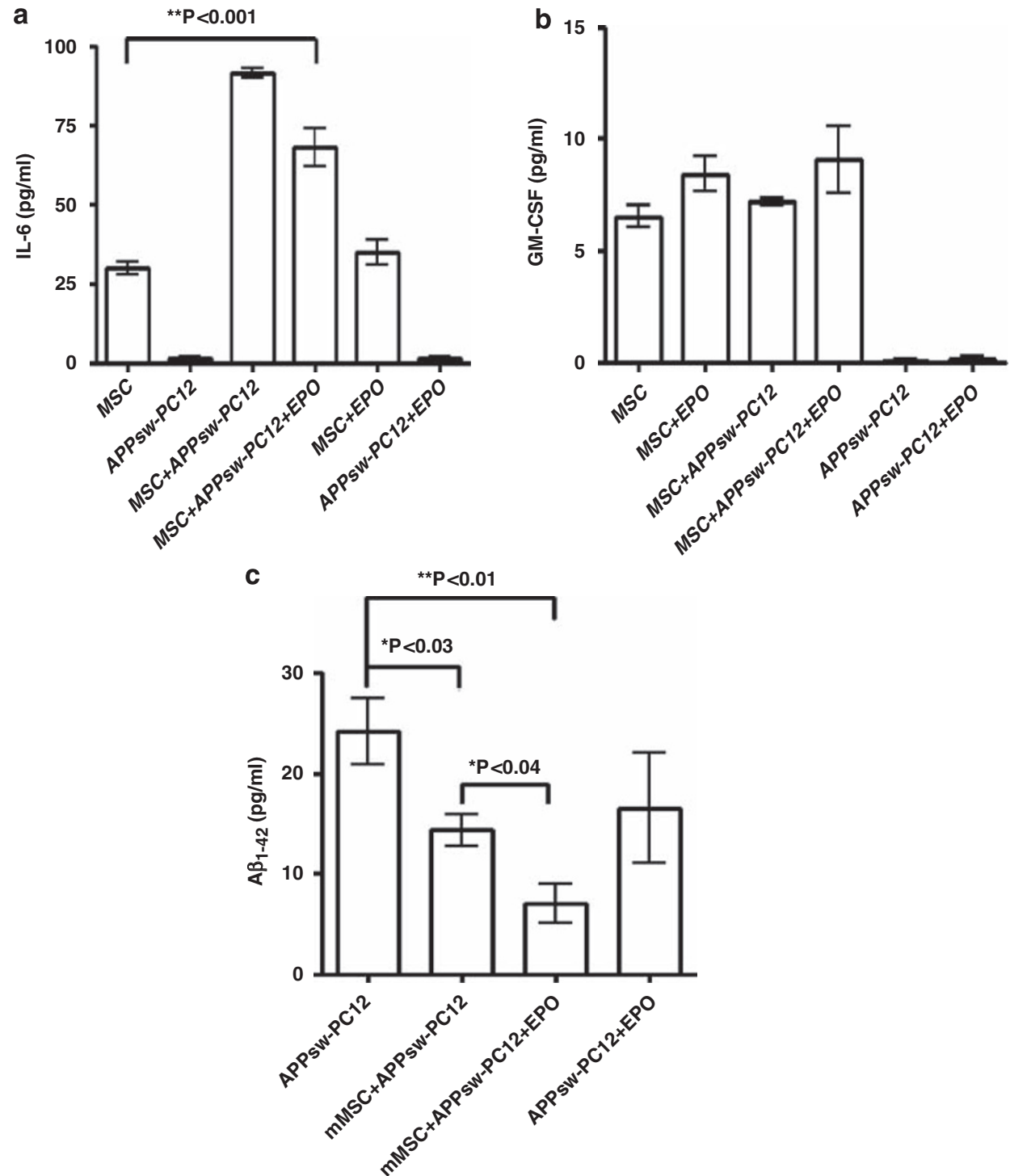

Figure 10 Multiplex analysis of cytokines released from murine $(\mathrm{m})$ MSC co-cultured with APPsw-PC12. The release of IL-6 (a) is threefold higher in co-cultures (MSC + APPsw-PC12) than those in control monocultures (MSC). EPO applied to co-cultures (MSC + APPsw-PC12 + EPO) significantly decreased the release of IL-6 $\left({ }^{\star \star} P<0.001\right.$, one-way ANOVA). IL-6 concentration in cell culture supernatants from monocultures of mMSC was not altered by application of EPO (cf. MSC versus MSC + EPO). Quantification of GM-CSF (b) did not show any changes in mono and co-cultures of MSC with APPsw-PC12 either in controls or in EPO-treated cultures. The quantification of Abeta $_{1-42}$ by ELISA in the cell culture supernatants (panel c) revealed that cocultivation of APPsw-PC12 with mMSC decreases the Abeta ${ }_{1-42}$ concentration (cf. APPsw-PC12 with mMSC + APPsw-PC12 in c). EPO additionally reduces the amount of Abeta $_{1-42}$ (cf. mMSC + APPsw-PC12 versus mMSC + APPsw PC12 + EPO in c) in co-cultures but not in monocultures of APPsw-PC12 (cf. APPsw-PC12 + EPO versus APPsw-PC12 in c). One-way ANOVA with Bonferroni's comparison was used for multiple comparisons between control and treated samples

Table 2 Oxygen partial pressure in gas, blood and tissues

\begin{tabular}{ll}
\hline Compartment & $\begin{array}{l}\text { Oxygen partial } \\
\text { pressure } \\
\text { (reference) }\end{array}$ \\
\hline Dry atmospheric air & $159 \mathrm{~mm} \mathrm{Hg}^{19}$ \\
Alveolar gas & $100 \mathrm{~mm} \mathrm{Hg}^{19}$ \\
Arterial blood & $95 \mathrm{~mm} \mathrm{Hg}^{19}$ \\
Mean capillary blood & $45 \mathrm{~mm} \mathrm{Hg}^{19}$ \\
Bone marrow & $55 \mathrm{~mm} \mathrm{Hg}^{21}$ \\
Brain tissue (7-12 $\mathrm{mm}$ below dura mater) & $33 \mathrm{~mm} \mathrm{Hg}^{21}$ \\
Brain tissue (12-17 mm below dura mater) & $33 \mathrm{~mm} \mathrm{Hg}_{21}$ \\
Brain tissue (17-22 mm below dura mater) & $26 \mathrm{~mm} \mathrm{Hg}^{21}$ \\
Brain tissue (22-27 mm below dura mater) & $24 \mathrm{~mm} \mathrm{Hg}^{21}$ \\
\hline
\end{tabular}

their ability to mobilize intracellular calcium is associated with stimulation of phospholipase $\mathrm{C}$, which in turn leads to the release of inositol-1,4,5-triphosphate $\left(\mathrm{IP}_{3}\right)$ and consequently of $\mathrm{Ca}^{2+}$ from intracellular stores into the cytosol. M2 and M4 receptors are primarily known to inhibit adenylyl cyclase activity and to reduce the concentration of cAMP. However, they were also shown to have a stimulatory effect on phospholipase $\mathrm{C}$ in some cell types. ${ }^{28} \mathrm{~A}$ transient increase of cytosolic $\left[\mathrm{Ca}^{2+}\right]$ in response to ACh in EPO-treated hMSC is most likely mediated through M1R and M3R with consequent activation of phospholipase $\mathrm{C}$ and $\mathrm{IP}_{3}$ release.

Regarding the question which mechanisms are involved in induction and maintenance of the neuron-like phenotype of 
MSC, we hypothesized that EPO could either (i) enhance the production of other growth factors, such as NGF or LIF, which are known to induce neuron-like differentiation in stem cells of different origin ${ }^{29,30}$ and/or (ii) activate directly the signaling systems such as the Wnt pathway that orchestrate the growth and differentiation fate of stem cells. ${ }^{31}$ NGF message levels remained unchanged in EPO-treated hMSC. Unlike NGF, LIF was upregulated by EPO under both normoxic and, most prominently, under HCs. LIF was recently shown to be upregulated in the ischemic brains and neural cultures exposed to oxygen/glucose deprivation. ${ }^{32}$ This hints at the possible induction of neuron-like differentiation of implanted MSC by LIF overexpressed in ischemic brain tissue.

A recent report showed that hypoxia suppresses Wnt signaling and $\beta$-catenin activation. ${ }^{33}$ Here we show that EPO induces the production of Wnt3a in hMSC under normoxic and, especially, hypoxic conditions. Moreover, this induction of Wnt3a by EPO under hypoxia was completely abolished by CRD-Fzd7, which is known to inhibit the activity of Wnt3a and to reduce the accumulation of $\beta$-catenin. ${ }^{17}$ Keeping in mind that EPO also upregulates the expression and functionality of $M 1 R$, it is possible that a cross talk between muscarinic and Wnt signaling underlies the neuroprotective effect of M1R activation through the inhibition of glycogen-synthase-kinase$3 \beta$ activity and stabilization of the cytoplasmic and nuclear $\beta$ catenin ${ }^{34}$ by which the shutdown of the Wnt pathway induced by Abeta toxicity is reversed.

In addition, Wnt signaling (especially through Wnt3a) inhibits the osteogenic differentiation of hMSC. ${ }^{35}$ Our results show that EPO-induced upregulation of ChAT, neprilysin, GLAST and LIF in hMSC upon hypoxia was abolished by CRD Fzd7. The effect of EPO on the ACh production by hMSC exposed to Glu was also sensitive to CRD Fzd7, which decreased ACh to the levels of the control. Presumably, EPO can stabilize the phenotype of neuron-like differentiated hMSC by increasing the production of Wnt3a, which in turn may prevent hMSC reprogramming. The better survival of EPO-treated hMSC on exposure to Glu and/or hypoxia may also be interconnected with Wnt3a activity. CRD Fzd7 abolished the anti-apoptotic effect of EPO under these neurotoxic conditions, as shown by quantification of TUNELpositive hMSC. The eightfold increase in TUNEL-positive cells on application of CRD Fzd7 either alone or in combination with EPO under normoxia or hypoxia may implicate an EPOindependent role of Fzd7 signaling in hMSC survival.

The possible therapeutic use of hMSC in AD depends on the resistance of the engrafted MSC to the toxic effects of Abeta. The cocultivation of mMSC with Abeta $_{1-42}$ and Abeta $_{1-40}$-producing rat APPsw-PC12 cells resulted in enhanced release of IL- 6 from mMSC. The toxic effect of Abeta on the CNS cells is reflected by cell death ${ }^{36}$ and an inflammatory response. ${ }^{37}$ The release of IL- 6 from $\mathrm{mMSC}$ in response to the exposure toward Abeta produced by APPsw$\mathrm{PC} 12$ cells is significantly reduced by application of EPO. The production of granulocyte-monocyte colony-stimulating factor (GM-CSF) by mMSC was not affected by cocultivation with APPsw-PC12; the concentration of GM-CSF was at a very low level, nearly equal to the basal levels of control cultures. Our data are concordant with previous studies reporting the decrease of IL-6 production in organ-specific cells and tissues in various disease models in response to EPO. ${ }^{38,39}$ As GM-CSF can be upregulated by Abeta, ${ }^{37}$ and in turn may increase the production of Abeta, ${ }^{40}$ our data suggest that engrafted MSC most likely will not harm the host tissue by additionally increasing the local GM-CSF levels. Moreover, our data show that EPO is capable of not only decreasing the inflammatory response of MSC to Abeta, but also enhances

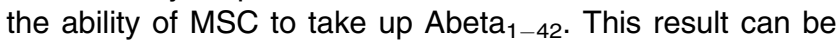
explained by the capacity of MSC to express neprilysin, a major Abeta-degrading enzyme of the brain. ${ }^{41}$ This effect of EPO seems to depend on the Wnt signaling pathway, as CRD Fzd 7 completely abolishes it under normoxia and hypoxia.

Our study points out the pivotal role of EPO in survival, functionality (electrophysiological features, expression of cholinergic and synaptic markers) and protective features (Glu-metabolizing activity) of hMSC under neurotoxic conditions characterized by hypoxia, Glu excess and the presence of Abeta that occur in a variety of neurodegenerative diseases. In MSC-based therapeutical approaches against neurodegenerative disorders, it should be kept in mind that the resistance of MSC to the pathological environment and their regenerative/replacing capacities can be improved by co-administration of EPO.

\section{Materials and methods}

BM preparation. Our study was approved by the institutional review board (ethical committee) of the University of Tübingen. BM was taken under sterile conditions from five donors (two female, three male, age: 16-74 years, no metabolic or neoplastic diseases) with informed consent during orthopedic operations: From each donor, $5 \mathrm{ml}$ of whole BM was collected in a sterile heparinized syringe. From each donor the hMSC were isolated, characterized and included into the study as a separate hMSC population. The results are given as means \pm S.E.M. of the recorded data from each hMSC population.

Isolation of $\mathbf{h M S C}$ and cell culture. To isolate $\mathrm{hMSC}$ from whole BM, we used the density gradient technique as previously described. ${ }^{42}$ Briefly, $5 \mathrm{ml} \mathrm{BM}$ was resuspended in $10 \mathrm{ml}$ phosphate-buffered saline (PBS) (Cambrex Bio Science, Verviers, Belgium) and laid over $15 \mathrm{ml}$ Lymphoflot (sodium diatrizoate $9.1 \%(\mathrm{w} / \mathrm{v})$, Ficoll $5.7 \%(\mathrm{w} / \mathrm{v})$; Biotest AG, Dreieich, Germany). After centrifugation (20 min at $1000 \times g$, rotor brake off), the mononuclear cells were harvested, washed twice with PBS, transferred to a $75-\mathrm{cm}^{2}$ culture flask (Corning Inc., Schiphol-Rijk, the Netherlands) and incubated $\left(37^{\circ} \mathrm{C}, 95 \%\right.$ humidified air, $\left.5 \% \mathrm{CO}_{2}\right)$ with $\alpha$-MEM (PAA, Cölbe, Germany), containing desoxyribonucleotides, ribonucleotides and 'ultra glutamine 1' (all from Lonza, Wuppertal, Germany), $100 \mathrm{IU} / \mathrm{ml}$ penicillin (Lonza), $100 \mu \mathrm{g} / \mathrm{ml}$ streptomycin (Lonza) and 10\% heat-inactivated fetal calf serum (FCS) (Cambrex Bio Science). After $24 \mathrm{~h}$, the non-adherent cells were removed and the adherent cells were cultured and characterized.

Basic characterization of hMSC by in vitro differentiation and FACS analysis. Mesenchymal stem cells are functionally characterized by in vitro differentiation assays. ${ }^{43}$ We evaluated the basic differentiation potential into three mesenchymal lineages: adipogenic, osteogenic and chondrogenic differentiation. The different hMSC populations were each treated either with adipogenic medium, osteogenic medium or normal medium (control) for 21 days, as previously described ${ }^{44}$ (modification: no addition of amphotericin B).

Adipogenic differentiation was performed using a commercially available differentiation kit (Lonza). A total of $1 \times 10^{6}$ cells per $\mathrm{cm}^{2}$ were seeded and cultured in normal medium. Reaching subconfluency, the medium was changed to adipogenic differentiation medium or control medium and the cells were cultured for 3 weeks. Thereafter, the cells were stained with oil red $\mathrm{O}$ for visualization of in vitro adipogenesis. For staining, after removal of the medium and washing twice with PBS, $2 \mathrm{ml}$ of $10 \%$ formalin were added followed by an incubation time of $30 \mathrm{~min}$. After removing the formalin and washing the cell layer with sterile water, $2 \mathrm{ml}$ of isopropanol (60\%, BioWhittaker, Verviers, Belgium) were added and kept for $2 \mathrm{~min}$. The isopropanol was removed and $2 \mathrm{ml}$ of a filtered working solution of oil red $\mathrm{O}$ 
(three parts oil red O stock solution ( $300 \mathrm{mg}$ oil red O powder (Sigma, Taufkirchen, Germany) $+100 \mathrm{ml} 99 \%$ isopropanol (Sigma)) + three parts deionized water) were pipetted onto cells and left there for $5 \mathrm{~min}$. Thereafter the plate was rinsed with tap water and the cells were counterstained with $2 \mathrm{ml}$ hematoxylin (Sigma) for $1 \mathrm{~min}$.

Osteogenic differentiation was performed using osteogenic medium containing normal medium with $10^{-8} \mathrm{M}$ dexamethasone (Sigma), $0.2 \mathrm{mM}$ ascorbic acid (Sigma) and $10 \mathrm{mM} \beta$-glycerolphosphate (Sigma). Reaching subconfluency, cells were incubated in osteogenic differentiation or control medium for 3 weeks. The osteogenic differentiated cells as well as control cells were cytochemically stained for alkaline phosphatase using a commercial staining kit according to the manufacturer's (Sigma) recommendations; after removal of the medium and washing twice with PBS, $2 \mathrm{ml}$ citrate fixative $(12.5 \mathrm{ml}$ citrate solution $+32.5 \mathrm{ml}$ acetone $+4 \mathrm{ml} 37 \%$ formaldehyde) were added for $1 \mathrm{~min}$, followed by staining with $2 \mathrm{ml}$ alkaline dye $(0.5 \mathrm{ml}$ sodium nitrite $+0.5 \mathrm{ml}$ FRV-alkaline solution $+22.5 \mathrm{ml}$ deionized water $+0.5 \mathrm{ml}$ naphtole AS-BI alkaline solution) for $30 \mathrm{~min}$. The cell layer was washed twice and counterstained with $2 \mathrm{ml}$ hematoxylin (Sigma) for $1 \mathrm{~min}$.

Chondrogenic differentiation was performed using a commercially available mesenchymal functional differentiation kit (Lonza). The MSCs were treated with the chondrogenic differentiation procedure; $250 \times 10^{3}$ cells were transferred into a $15 \mathrm{ml}$ tube. After centrifugation $(200 \times \mathrm{g}), 0.5 \mathrm{ml}$ chondrogenic differentiation medium were added and replaced every $3-4$ days. The cell suspension was cultured in the tube forming a solid pellet. After 14 days, the chondrocyte pellet was removed, squeezed on a glass slide and stained with 1\% Alcian Blue 8GX (Serva, Heidelberg, Germany) in $3 \%$ acetic acid ( $\mathrm{pH} 2.5$ ).

FACS analysis was carried out with a FACScan instrument (BD Biosciences, San Jose, CA, USA) using BD CellQuest Pro software. At subconfluency $\left(1 \times 10^{6}\right.$ cells), the cells were detached from flasks at subconfluency with trypsin/EDTA (Lonza) and washed with PBS. Each sample contained a cell suspension with $5 \times 10^{5}$ cells in FACS buffer (PBS $+1 \%$ bovine serum albumin (Sigma) $+0.1 \%$ FCS (Lonza)). The PE-conjugated antibody (Anti-human-CD14, -CD29, -CD34, -CD43, -CD44, -CD45, -CD59, -CD73, -CD90, -CD105, -CD106, -CD117, -CD133, -CD146, -CD166, HLA class I, HLA class II) was added. After an incubation time of $20 \mathrm{~min}$ and two washing steps, the sample was ready for analysis. All antibodies were from BD Biosciences.

The hMSC showed the following surface epitope pattern (FACS analysis): negative for CD14, CD34, CD43, CD45, CD133 and HLA class II, and positive for CD29, CD44, CD59, CD73, CD90, CD105, CD106, CD117, CD146, CD166 and HLA class I (data not shown).

Exposure to hypoxia, Glu, EPO and CRD Fzd7. For the experiments on neurogenic differentiation of hMSC, cells were cultured in Dulbecco's modified Eagle's medium (DMEM) supplemented with $10 \% \mathrm{FCS}, 100 \mathrm{U} / \mathrm{ml}$ penicillin, $100 \mu \mathrm{g} /$ $\mathrm{ml}$ streptomycin and $100 \mathrm{mM}$ pyruvate (supplemented DMEM, Biochrom, Berlin, Germany). Cultures were maintained at $37^{\circ} \mathrm{C}$ under NCs in a humidified atmosphere of $90 \%$ air and $10 \% \mathrm{CO}_{2}$. HMSCs were expanded and processed for immunocytochemistry, qPCRs, western blots, GS activity and determinations of Abeta $_{1-42}$, ACh and LDH after the third passage.

Before all measurements described below, the culture medium was removed and replaced by DMEM with or without $5 \mathrm{U} / \mathrm{ml}$ human recombinant erythropoietin (Neorecormon, Hoffmann-La Roche, Grenzach-Wyhlen, Germany) and/or Glu $(1 \mathrm{mM})$. For the experiments involving Wnt pathway blockade, the CRD of mouse Frizzled-7 (Fzd7) was used (R\&D systems, Wiesbaden-Nordenstadt, Germany). Mouse Fzd7 shares $99 \%$ identity with the human ortholog in the CRD. Preincubation with CRD Fzd7 $(500 \mathrm{ng} / \mathrm{ml})$ alone was performed for $1 \mathrm{~h}$ before the medium containing Glu and EPO was added, and the incubation was continued for another $48 \mathrm{~h}$. To evaluate the effect of these additives under $\mathrm{NC}$ and $\mathrm{HC}$, one set of the cultures was incubated at $10 \% \mathrm{CO}_{2}$ in air (normoxia), the other set was incubated at $10 \% \mathrm{CO}_{2}$ and $1 \% \mathrm{O}_{2}$ in $\mathrm{N}_{2}$ (hypoxia) for $48 \mathrm{~h}$ at $37^{\circ} \mathrm{C}$.

Determination of cytotoxicity. For determination of cell viability and cytotoxic effects of hypoxia and/or Glu on hMSC, the cells were cultured in 96-well plates. LDH in the cell culture supernatant was measured by the CytoTox 96 NonRadioactive Cytotoxicity Assay (Promega, Mannheim, Germany). To determine $\mathrm{LDH}, 50 \mu \mathrm{l}$ of the supernatant of each well were transferred to a separate assay plate, mixed with $50 \mu \mathrm{l}$ substrate mix and incubated for $30 \mathrm{~min}$ at room temperature (RT). The enzymatic conversion of a tetrazolium salt into a red formazan product was stopped by adding $50 \mu \mathrm{l}$ stop solution, and the absorbance was recorded at $490 \mathrm{~nm}$ in a 96-well plate reader (Sunrise, Tecan, Crailsheim, Germany). Quantification was carried out by external standardization with LDH activities in the range between $0-800 \mathrm{U} / \mathrm{ml}$ in DMEM (standard supplied in the test kit). The absorbance value of a culture medium control was used to normalize the values obtained from the samples.

Quantification of $\mathrm{ACh}$ in the cell culture supernatant of hMSC. For quantification of ACh, hMSCs were cultured in 96-well plates using choline-free HBSS (H 8264, Sigma) supplemented with $10 \%$ FCS, $100 \mathrm{U} / \mathrm{ml}$ penicillin, $100 \mu \mathrm{g} / \mathrm{ml}$ streptomycin and $100 \mathrm{mM}$ pyruvate. A $100 \mu \mathrm{l}$ aliqot of cell culture supernatant was used and measured with the AmplexRed Acetylcholine/ Acetylcholineesterase Assay Kit (A12217, Molecular Probes/Invitrogen, Carlsbad, CA, USA) according to the manufacturer's manual. In brief, in this assay ACh is monitored indirectly using 10-acetyl-3,7-dihydroxyphenoxazine (Amplex Red Reagent), a sensitive fluorogenic probe for $\mathrm{H}_{2} \mathrm{O}_{2}$, an end product of oxidized choline. First, acetylcholinesterase converts $\mathrm{ACh}$ to choline, which is in turn oxidized by choline oxidase to betaine and $\mathrm{H}_{2} \mathrm{O}_{2}$. The latter reacts with the Amplex Red reagent in a $1: 1$ stoichiometry to generate the fluorescent product resorufin. Fluorescence was monitored in a fluorescence plate reader (GENios Plus, Tecan) using $550 \mathrm{~nm}$ for excitation and $595 \mathrm{~nm}$ for emission after $1 \mathrm{~h}$ of incubation with the reaction mix. A standard curve was prepared in the range of $0-100 \mu \mathrm{M}$ and assayed simultaneously with the samples. Data were corrected for background fluorescence by subtracting the values derived from an ACh-free control.

Multiplex analysis of cytokine release from co-cultures of murine (m) MSC and rat PC12 overexpressing the human APP gene bearing the Swedish mutation. Before cocultivation, rat APPswPC12 (PC12SWQ8) cells were cultured in DMEM with 10\% FCS, $5 \%$ horse serum, $100 \mathrm{U} / \mathrm{ml}$ penicillin, $100 \mu \mathrm{g} / \mathrm{ml}$ streptomycin, $100 \mathrm{mM}$ pyruvate and G-418-BC (Biochrom), whereas mMSC isolated from the BM of three female mice (age: 6 weeks) were cultured with $\alpha$-MEM (BioWhittaker) supplemented with $10 \%$ FCS (Lonza) and antibiotics/antimycotics (containing $100 \mathrm{U} / \mathrm{ml}$ penicillin, $100 \mu \mathrm{g} / \mathrm{ml}$ streptomycin sulfate and $0.25 \mu \mathrm{g} / \mathrm{ml}$ amphotericin B) from Sigma. Multipotency of the mMSC was evaluated by adipogenic, osteogenic and chondrogenic differentiation. PC12SWQ8 cells were seeded in 6-cm Petri dishes $\left(2 \times 10^{6}\right.$ cells per dish) and cultured for $24 \mathrm{~h}$ under NCs. After $24 \mathrm{~h}, 3 \times 10^{5} \mathrm{mMSC}$ were added to PC12SWQ8 cultures. The monocultures of mMSC and PC12SWQ8 cells, as well as their co-cultures were in each case incubated in the presence or absence of EPO $(5 \mathrm{U} / \mathrm{ml})$ and under either normoxic or hypoxic culture conditions for $48 \mathrm{~h}$. Thereafter, the respective cell culture supernatants were centrifuged $(350 \times g$, $8 \mathrm{~min}, 4^{\circ} \mathrm{C}$ ) and frozen $\left(-80^{\circ} \mathrm{C}\right)$ until the measurement of the cytokines by multiplex analysis, which was performed as described elsewhere. ${ }^{45}$ Briefly, $50 \mu \mathrm{l}$ medium from each dish was used for detection of interleukin-1 beta (IL-1 $\beta$ ), IL-2, IL-4, IL-5, IL-6, IL-10, IL-12 (p70), GM-CSF, interferon-gamma (IFN- $\gamma$ ) and tumor necrosis factor-alpha (TNF- $\alpha)$. The quantification of these cytokines was performed with a Beadlyte Mouse Multi-Cytokine BeadmasterTM Kit (Upstate, Lake Placid, NY, USA) and a Luminex-100 system (Luminex Corporation, Austin, TX, USA), according to the manufacturer's instructions. The cytokine concentrations in the cell culture supernatants were extrapolated from their respective standard curves by 5-parameter logistic analysis.

Quantification of Abeta $_{1-42}$ in the cell culture supernatant of mMSC and rat APPsw-PC12 (PC12SWQ8) cells. For quantification of Abeta $_{1-42}, 50 \mu$ lof the same cell culture supernatant as for the cytokine assay were taken and assayed with a highly sensitive enzyme-linked immunosorbent assay (hAmyloid $\beta 42$ ELISA, The GENETICS Company, Zürich, Switzerland) according to the manufacturer's manual.

Immunofluorescence analyses. For the immunofluorescence studies, hMSCs $\left(2.5 \times 10^{5}\right)$ were grown under normoxic and hypoxic conditions in $60-\mathrm{mm}$ cell culture dishes (BD Falcon, Heidelberg, Germany) containing coverslips. After fixation with $-20^{\circ} \mathrm{C}$ cold methanol, the cells were rinsed with PBS and incubated with primary antibodies diluted in PBS for $1 \mathrm{~h}$ at RT. Dilutions of primary antibodies were as follows: anti-EPOR (1:50; rabbit polyclonal, Santa Cruz, Santa Cruz, CA, USA), anti-GFAP (1:10; mouse monoclonal, Progen, Heidelberg, Germany), anti$\beta$-tubulin III clone TUJ1 (1:250, mouse monoclonal, R\&D Systems), anti-GLAST (1:100, rabbit polyclonal, Abcam, Cambridge, UK), anti-EPO (1:75, mouse monoclonal, AbD Serotec, Oxford, UK), anti-synaptophysin (1:50, US Biological, rabbit polyclonal, Swampscott, MA, USA) or anti-GS $(1: 100$, rabbit polyclonal, Sigma), or anti-human neuronal nuclei-specific protein $(1: 25$, mouse monoclonal, Chemicon International, Nürnberg, Germany). The cells were washed twice with 
PBS and incubated in the dark with the secondary antibodies, fluorescein isothiocyanate-conjugated goat anti-rabbit $\lg G(1: 100)$ or goat anti-mouse $\lg G$ $(1: 100)$, and Cy3-conjugated goat anti-mouse $\lg G(1: 800)$ or goat anti-rabbit IgG ( $1: 800$; all from Jackson ImmunoResearch, Newmarket, UK), for $1 \mathrm{~h}$ at RT. After washing twice with PBS containing $0.1 \%$ Triton X-100 (Sigma), samples were mounted with Vectashield medium (Vector Laboratories, Burlingame, CA, USA) containing DAPI and assessed by fluorescent microscopy.

Western blot analyses. Western blotting was carried out using protein lysates from $2.5 \times 10^{5}$ cells. Protein concentrations were measured using the Bradford assay. For each lane, $50 \mu \mathrm{g}$ of proteins were subjected to SDS-PAGE in a $12.5 \%$ gel and transferred to PVDF membranes by tank blotting. Membranes were blocked in $0.66 \%$ (v/w) I-Block in PBS (Tropix, Applied Biosystems, Weiterstadt, Germany) for $1.5 \mathrm{~h}$ and were then incubated at $4{ }^{\circ} \mathrm{C}$ overnight with antibodies against ChAT (1:1000, Biozol, Eching, Germany), synaptophysin (1:100, US Biological), Wnt3a (dilution 1:1000, Cell Signaling Technology, Frankfurt, Germany), leukemia-inhibitory factor (LIF, 1:200, Santa Cruz Biotechnology), EPO receptor (EPOR, 1:300, Santa Cruz Biotechnology, Heidelberg, Germany), neprilysin (1:1000, R\&D systems), GLAST (1:5000, Chemicon International), $\beta$-catenin (1:1000, BD, BD Biosciences), GFAP mouse (dilution 1: 1000, Progen) and GAPDH (1: 1000, Chemicon International; loading control). For visualization of antibody binding, membranes were incubated for $2 \mathrm{~h}$ at RT with alkaline phosphatase-conjugated goat anti-rabbit or anti-mouse or rabbit anti-sheep or anti-guinea pig secondary antibodies (Tropix), diluted 1:10.000 in PBS and thereafter exposed to CDP-Star (Tropix) as chemoluminescence substrate for $1 \mathrm{~h}$ in the dark room. Signal intensities were recorded using a CCD camera system and sub-saturated images were analyzed semi-quantitatively by densitometry using the TINA software (version 2.09g. Raytest, Straubenhardt, Germany). Data were normalized to the respective densitometric values of normoxic controls and expressed as percent values.

GS activity assay. The cells $\left(3 \times 10^{4}\right.$ per well) were washed once with ice-cold PBS and lysed by adding $125 \mu \mathrm{l} 50 \mathrm{mM}$ imidazole/ $/ \mathrm{HCl}$ buffer $(\mathrm{pH}$ 7.2). After a freezing-thawing cycle $\left(-80^{\circ} \mathrm{C}\right.$ to RT), $25 \mu$ of the lysates were pipetted into a separate 96-well plate for protein determination. The remaining $100 \mu \mathrm{l}$ lysates were used for the GS activity assay. GS was determined by measuring its $\gamma$ glutamyltransferase activity by following the formation of a complex between the reaction product $\gamma$-mono-hydroxamate and ferric chloride. The reaction was started by addition of $100 \mu$ l of reaction mixture $(50 \mathrm{mM}$ imidazole/ $\mathrm{HCl}$ buffer $\mathrm{pH} 7.2,2 \mathrm{mM}$ $\mathrm{MnCl}_{2}, 25 \mathrm{mM}$ sodium arsenate, $0.16 \mathrm{mM} \mathrm{ADP}, 50 \mathrm{mM}$ L-glutamine and $25 \mathrm{mM} \mathrm{NH}_{2}$ $\mathrm{OH} \cdot \mathrm{HCl}$ ) and incubated at $37^{\circ} \mathrm{C}$ for $2 \mathrm{~h}$. The reaction was stopped by adding $400 \mu \mathrm{l}$ stop solution consisting of $0.37 \mathrm{M} \mathrm{FeCl}_{3}, 0.67 \mathrm{M} \mathrm{HCl}$ and $0.2 \mathrm{M}$ trichloroacetic acid. Precipitated proteins were removed by centrifugation at $15000 \times g\left(5 \mathrm{~min}, 4^{\circ} \mathrm{C}\right)$ and the absorbance of the supernatant was measured at $540 \mathrm{~nm}$. Ten standards of $\gamma$. mono-hydroxamate dissolved in lysis buffer were prepared in the range of $0-5 \mu \mathrm{mol}$ and treated equally. Activity of GS was determined based on a standard value of $1 \mathrm{U}$ as the amount of the enzyme required for generation of $1 \mu \mathrm{mol} \gamma$-monohydroxamate/min. The raw data expressed in $\mathrm{U} / \mathrm{mg}$ protein were normalized against the respective normoxic or hypoxic control in the presence or absence of $1 \mathrm{mM} \mathrm{Glu}$ and expressed as percentages.

Preparation of cDNA and quantification by real-time PCR. Mesenchymal stem cell total RNA was extracted from hMSCs by the RNeasy Mini Kit (Qiagen, Hilden, Germany). Except for the detection of $\beta$-tubulin III mRNA (see below), reverse transcription of total RNA was carried out with Superscript II and Oligo(dT) primers (Invitrogen). Total RNA ( $360 \mathrm{ng}$ ) was reverse transcribed in a $20 \mu \mathrm{l}$ reaction and $1 \mu \mathrm{l}$ of this reaction was subjected to qPCR, using the Platinum-SYBR Green $\rightarrow$ qPCR Supermix (Invitrogen), $0.6 \mu \mathrm{M}$ forward (sense, s) and reverse (antisense, as) primers and $100 \mathrm{nM} \mathrm{ROX}$. Oligonucleotide primers for different genes were designed with the Primer3 software (http://frodo.wi.mit.edu/cgibin/primer3/primer3_www.cgi). The primers used for qPCR are listed in Table 3.

For the muscarinic receptors, primers were chosen within the coding exon to ensure quantification of all transcripts (muscarinic receptor presents different splice variants in the $5^{\prime}$ UTR). To control genomic contamination of the mRNA preparation, three additional sense primers, matching to intronic regions of the muscarinic receptor genes (marked by an asterisk) were used in combination with the respective antisense primer in the qPCR. For $\beta_{2}$-microglobulin and NGF transcript amplification, intron-flanking primers were used.
Table 3 Primer sequences for qPCR

\begin{tabular}{lll}
\hline Gene & Direction & $\mathbf{5}^{\prime} \mathbf{- 3}$ ' sequence \\
\hline M1R & S & TGCTGACCTCATCATCGGTA \\
& As & CGGAGAAGTAGCGGTCAAAGC \\
M2R & $\mathrm{s}^{*}$ & TCCACTTATGGCTGGGAAAG \\
& $\mathrm{S}$ & GGCCATTCCAAAGATGAGAA \\
& As & ACAATCTTGCGGGCTACAATATT \\
M3R & $\mathrm{s}^{*}$ & GGCTCTGGTACTTGCAGCTC \\
& $\mathrm{S}$ & GCCTGTGCCGATCTGATTAT \\
& As & GGCCTCGTGATGGAAAAGTA \\
$\beta_{2}-$-microglobulin & $\mathrm{S}$ & AGAAATGAGAAAAATGTGGGAAAA \\
NGF & As & TTTCATCCATCCGACATTGA \\
& S & TCCCGATGATGCTGCTTACA \\
& As & CAGTGTCAAGGGAATGCTGA \\
& & \\
\hline
\end{tabular}

Except in the case of $\beta$-tubulin III (see below), PCR was carried out in an MX $3000 \mathrm{P}$ instrument (Stratagene, La Jolla, CA, USA) using the following protocol: $2 \mathrm{~min}$ at $50^{\circ} \mathrm{C}, 2 \mathrm{~min}$ at $95^{\circ} \mathrm{C}$, and 50 cycles of $15 \mathrm{~s}$ at $95^{\circ} \mathrm{C}$ and $30 \mathrm{~s}$ at $60^{\circ} \mathrm{C}$. Threshold cycle $\left(C_{T}\right)$ values were set within the exponential phase of PCR and normalization was performed to $\beta_{2}$-microglobulin for each sample to generate $\Delta \mathrm{C}_{T}$ values. A product melting curve was recorded to confirm a single amplicon. The correct product size was verified by agarose gel electrophoresis. The extracted total RNA and the GPCR reaction were tested for genomic contamination (additional primers annealing in intron regions listed in the Table 3 ). There was no significant genomic contamination in any RNA preparation.

Quantification of $\beta$-tubulin III mRNA in hMSC. For the determination of $\beta$-tubulin III mRNA by qPCR, $500 \mathrm{ng}$ of total RNA was reverse transcribed with AMV reverse transcriptase (PEQ-Lab, Erlangen, Germany), random primers (Promega) and oligo(dT)15 primer (Promega). Real-time PCR assays were carried out using the LightCycler FastStart DNA Master SYBR Green I system (Roche, Mannheim, Germany) in the Light Cycler 2.0 instrument. PCR was carried out with $2 \mu \mathrm{l}$ of reverse transcriptase product in $10 \mu \mathrm{l} \mathrm{PCR} \mathrm{mix} \mathrm{for} \mathrm{a} \mathrm{total} \mathrm{of} 45$ cycles. After $10 \mathrm{~min}$ at $95^{\circ} \mathrm{C}$ for polymerase activation, 45 cycles of PCR followed (denaturation at $95^{\circ} \mathrm{C}$ for $5 \mathrm{~s}$, annealing at $63^{\circ} \mathrm{C}$ for $10 \mathrm{~s}$, extension at $72^{\circ} \mathrm{C}$ for $9 \mathrm{~s}$ ). A melting curve analysis was subsequently carried out to confirm the presence of a uniform PCR product. The primers used were $5^{\prime}$-CCA TTC TGG TGG ACC TGG AGC CTG GAA- $3^{\prime}$ (sense) and $5^{\prime}$-GCT GGA AGC CCT GCA GGC AGT CAC AAT-3' (antisense). The data are shown as relative expression ratios with respect to the mean of the normoxic control.

Calcium imaging. The function of MSC ACh receptors was analyzed by calcium imaging using a Zeiss Axioskop (Carl Zeiss AG, Jena, Germany) equipped with an imaging system from Visitron Systems (Puchheim, Germany) and the Metafluor 6.2 imaging software (Universal Imaging/Molecular Devices, Downingtown, PA, USA). hMSC from hypoxic controls ( $48 \mathrm{~h}$ incubation under $\mathrm{HC})$ and those treated with EPO $(5 \mathrm{U} / \mathrm{ml})$ under hypoxia for $48 \mathrm{~h}$ were loaded with the $\mathrm{Ca}^{2+}$-sensitive fluorescent dye, Fura-2, by incubation with a solution containing $150 \mathrm{mM} \mathrm{NaCl}, 5 \mathrm{mM} \mathrm{KCl}, 2 \mathrm{mM} \mathrm{CaCl}, 2 \mathrm{mM} \mathrm{MgCl}$, $10 \mathrm{mM}$ HEPES, $30 \mathrm{mM}$ glucose and $2 \mu \mathrm{M}$ fura-2 acetoxymethyl ester, and $0.04 \%$ Pluronic for $20-30 \mathrm{~min}$ at $37^{\circ} \mathrm{C}$. Fluorescence was recorded before and after exposure to ACh (Sigma). The final ACh concentration in the bath solution was $10 \mu \mathrm{M}$. In control experiments, the muscarinic ACh antagonist atropine sulfate (Sigma) was used at a concentration of $500 \mathrm{nM}$.

Statistical analyses. All data presented in this study on hMSC obtained from five different donors were analyzed by Student's $t$-test for single comparisons and one-way ANOVA with Bonferroni test for multiple comparisons. Experiments were carried out separately on each of the five patient samples (3-6 replicates from each patient sample per condition). Thereafter, all data were included into the statistical analyses. The data shown in the diagrams include the pooled data of separately analyzed experiments. One representative experiment was chosen for the figures showing western blots (Figure 7) with the respective densitometric analyses (Table 1) and immunofluorescence (Figures 2, 3, 5 and 6). The data are presented as means \pm S.E.M.; $P<0.05$ was considered significant. 
Acknowledgements. The technical assistance by Mrs. Ursula HermanutzKlein is gratefully acknowledged. We appreciate the support of Dr. Martina Toelge (Microbionix, Regensburg, Germany) in performing multiplex analysis.

1. Kim SS, Yoo SW, Park TS, Ahn SC, Jeong HS, Kim JW et al. Neural induction with neurogenin1 increases the therapeutic effects of mesenchymal stem cells in the ischemic brain. Stem Cells 2008; 26: 2217-2228; e-pub ahead of print 10 July 2008.

2. Honma T, Honmou O, Lihoshi S, Harada K, Houkin K, Hamada H. Intravenous infusion of immortalized human mesenchymal stem cells protects against injury in a cerebral ischemia model in adult rat. Exp Neurol 2006; 199: 56-66.

3. Park HJ, Lee PH, Bang OY, Lee G, Ahn YH. Mesenchymal stem cells therapy exerts neuroprotection in a progressive animal model of Parkinson's disease. J Neurochem 2008; 107: 141-151; e-pub ahead of print 28 July 2008.

4. Pacary E, Legros H, Valable S, Duchatelle P, Lecocq M, Petit E et al. Synergistic effects of $\mathrm{CoCl}(2)$ and ROCK inhibition on mesenchymal stem cell differentiation into neuron-like cells. J Cell Sci 2006; 119: 2667-2678.

5. Webster NJ, Ramsden M, Boyle JP, Pearson HA, Peers C. Amyloid peptides mediate hypoxic increase of L-type Ca2+ channels in central neurones. Neurobiol Aging 2006; 27 : 439-445.

6. Lassmann H, Reindl M, Rauschka H, Berger J, Aboul-Enein F, Berger T et al. A new paraclinical CSF marker for hypoxia-like tissue damage in multiple sclerosis lesions. Brain 2003; 126: 1347-1357

7. Decker MJ, Jones KA, Solomon IG, Keating GL, Rye DB. Reduced extracellular dopamine and increased responsiveness to novelty: neurochemical and behavioral sequelae of intermittent hypoxia. Sleep 2005; 28: 169-176.

8. Theus MH, Wei L, Cui L, Francis K, Hu X, Keogh C et al. In vitro hypoxic preconditioning of embryonic stem cells as a strategy of promoting cell survival and functional benefits after transplantation into the ischemic rat brain. Exp Neurol 2008; 210: 656-670.

9. Tilleux S, Hermans E. Neuroinflammation regulation of glial glutamate uptake in neurological disorders. J Neurosci Res 2007; 85: 2059-2070.

10. Gonzalez FF, McQuillen P, Mu D, Chang Y, Wendland M, Vexler Z et al. Erythropoietin enhances long-term neuroprotection and neurogenesis in neonatal stroke. Dev Neurosci 2007; 29: 321-330

11. Zhang J, Li Y, Cui Y, Chen J, Lu M, Elias SB, Chopp M. Erythropoietin treatment improves neurological funtional recovery in EAE mice. Brain Res. 2005; 1034: 34-39.

12. Ehrenreich H, Fischer B, Norra C, Schellenberger F, Stender N, Stiefel M et al. Exploring recombinant human erythropoietin in chronic progressive multiple sclerosis. Brain 2007; 130: $2577-2588$.

13. Chong ZZ, Li F, Maiese K. Erythropoietin requires NF-kappaB and its nuclear translocation to prevent early and late apoptotic neuronal injury during beta-amyloid toxicity. Curr Neurovasc Res 2005; 2: 387-399.

14. Xue $Y Q$, Zhao LR, Guo WP, Duan WM. Intrastriatal administration of erythropoietin protects dopaminergic neurons and improves neurobehavioral outcome in a rat model of Parkinson's disease. Neuroscience 2007; 146: 1245-1258.

15. Danielyan L, Mueller L, Proksch B, Kabisch D, Weller M, Wiesinger $\mathrm{H}$ et al. Similar protective effects of $B Q-123$ and erythropoietin on survival of neural cells and generation of neurons upon hypoxic injury. Eur J Cell Biol 2005; 84: 907-913.

16. Esneault E, Pacary E, Eddi D, Freret T, Tixier E, Toutain J et al. Combined therapeutic strategy using erythropoietin and mesenchymal stem cells potentiates neurogenesis after transient focal cerebral ischemia in rats. J Cereb Blood Flow Metab 2008; 28: 1552-1563.

17. Kemp CR, Willems E, Wawrzak D, Hendrickx M, Agbor Agbor T, Leyns L. Expression of Frizzled5, Frizzled7, and Frizzled10 during early mouse development and interactions with canonical Wnt signaling. Dev Dyn 2007; 236: 2011-2019.

18. Zwezdaryk KJ, Coffelt SB, Figueroa YG, Liu J, Phinney DG, LaMarca HL et al. Erythropoietin, a hypoxia-regulated factor, elicits a pro-angiogenic program in human mesenchymal stem cells. Exp Hematol 2007; 35: 640-652.

19. Robinson SR. Neuronal expression of glutamine synthetase in Alzheimer's disease indicates a profound impairment of metabolic interactions with astrocytes. Neurochem In 2000; 36: 471-482.

20. de Hemptinne I, Vermeiren C, Maloteaux JM, Hermans E. Induction of glial glutamate transporters in adult mesenchymal stem cells. J Neurochem 2004; 91: 155-166.

21. Habler OP, Messmer KF. The physiology of oxygen transport. Transfus Sci 1997; 18: 425-435.

22. Harrison JS, Rameshwar P, Chang V, Bandari P. Oxygen saturation in the bone marrow of healthy volunteers. Blood 2002; 99: 394.
23. Dings J, Meixensberger J, Jager A, Roosen K. Clinical experience with 118 brain tissue oxygen partial pressure catheter probes. Neurosurgery 1998; 43: 1082-1095.

24. Tsang SW, Pomakian J, Marshall GA, Vinters HV, Cummings JL, Chen CP et al. Disrupted muscarinic M1 receptor signaling correlates with loss of protein kinase $C$ activity and glutamatergic deficit in Alzheimer's disease. Neurobiol Aging 2007; 28 1381-1387.

25. Caccamo A, Oddo S, Billings LM, Green KN, Martinez-Coria H, Fisher A et al. M1 receptors play a central role in modulating AD-like pathology in transgenic mice. Neuron 2006; 49: 671-682.

26. Henry-Feugeas MC. Alzheimer's disease in late-life dementia: a minor toxic consequence of devastating cerebrovascular dysfunction. Med Hypotheses 2008; 70: 866-875.

27. Hoogduijn MJ, Cheng A, Genever PG. Functional nicotinic muscarinic receptors on mesenchymal stem cells. Stem Cells Dev 2008; 18: 103-112.

28. Zhu X, Birnbaumer L. G protein subunits and the stimulation of phospholipase $\mathrm{C}$ by Gs-and Gi-coupled receptors: lack of receptor selectivity of Galpha(16) and evidence for a synergic interaction between Gbeta gamma and the alpha subunit of a receptor activated $G$ protein. Proc Natl Acad Sci USA 1996; 93: 2827-2831.

29. Arien-Zakay H, Nagler A, Galski H, Lazarovici P. Neuronal conditioning medium and nerve growth factor induce neuronal differentiation of collagen-adherent progenitors derived from human umbilical cord blood. J Mol Neurosci 2007; 32: 179-191.

30. Walton $\mathrm{RM}$, Wolfe $\mathrm{JH}$. In vitro growth and differentiation of canine olfactory bulb-derived neural progenitor cells under variable culture conditions. J Neurosci Methods 2008; 169 158-167.

31. Katoh M. WNT signaling in stem cell biology and regenerative medicine. Curr Drug Targets 2008; 9: 565-570.

32. Slevin M, Krupinski J, Mitsios N, Perikleous C, Cuadrado E, Montaner J et al. Leukaemia inhibitory factor is over-expressed by ischaemic brain tissue concomitant with reduced plasma expression following acute stroke. Eur J Neurol 2008; 15: 29-37.

33. Lim JH, Chun YS, Park JW. Hypoxia-inducible factor-1alpha obstructs a Wnt signaling pathway by inhibiting the hARD1-mediated activation of beta-catenin. Cancer Res. 2008 68: 5177-5184.

34. Farías GG, Godoy JA, Hernández F, Avila J, Fisher A, Inestrosa NC. M1 muscarinic receptor activation protects neurons from beta-amyloid toxicity. A role for Wnt signaling pathway. Neurobiol Dis 2004; 17: 337-348.

35. de Boer J, Siddappa R, Gaspar C, van Apeldoorn A, Fodde R, van Blitterswijk C. Wnt signaling inhibits osteogenic differentiation of human mesenchymal stem cells. Bone 2004; 34: 818-826.

36. Bisaglia M, Venezia V, Piccioli P, Stanzione S, Porcile C, Russo C et al. Acetaminophen protects hippocampal neurons and $\mathrm{PC} 12$ cultures from amyloid beta-peptides induced oxidative stress and reduces NF-kappaB activation. Neurochem Int 2002; 41: 43-54.

37. Patel NS, Paris D, Mathura V, Quadros AN, Crawford FC, Mullan MJ. Inflammatory cytokine levels correlate with amyloid load in transgenic mouse models of Alzheimer's disease. J Neuroinflammation 2005; 11: 1-9.

38. Strunk T, Härtel C, Temming P, Matzke N, Zimmer J, Schultz C. Erythropoietin inhibits cytokine production of neonatal and adult leukocytes. Acta Paediatr 2008; 97: 16-20.

39. Kumral A, Baskin H, Yesilirmak DC, Ergur BU, Aykan S, Genc S et al. Erythropoietin attenuates lipopolysaccharide-induced white matter injury in the neonatal rat brain. Neonatology 2007; 92: 269-278.

40. Volmar CH, Ait-Ghezala G, Frieling J, Paris D, Mullan MJ. The granulocyte macrophage colony stimulating factor (GM-CSF) regulates amyloid beta (Abeta) production. Cytokine 2008; 42: 336-344.

41. Iwata N, Tsubuki S, Takaki Y, Shirotani K, Lu B, Gerard NP et al. Metabolic regulation of brain Abeta by neprilysin. Science 2001; 292: 1550-1552.

42. Colter DC, Sekiya I, Prockop DJ. Identification of a subpopulation of rapidly self-renewing and multipotential adult stem cells in colonies of human marrow stromal cells. Proc Natl Acad Sci USA 2001; 98: 7841-7845.

43. Schäfer R, Dominici M, Muller I et al. Progress in characterization, preparation and clinical applications of non-hematopoietic stem cells, 29-30 September 2006, Tubingen, Germany. Cytotherapy 2007; 9: 397-405.

44. Kern S, Eichler H, Stoeve J, Kluter H, Bieback K. Comparative analysis of mesenchymal stem cells from bone marrow, umbilical cord blood or adipose tissue. Stem Cells 2006; 24: 1294-1301.

45. Danielyan L, Lourhmati A, Verleysdonk S, Kabisch D, Proksch B, Thiess U et al. Angiotensin receptor type 1 blockade in astroglia decreases hypoxia-induced cell damage and TNF alpha release. Neurochem Res 2007; 32: 1489-1498. 